\title{
Phosphatidylethanolamine Metabolism in Health and Disease
}

\author{
Elizabeth Calzada ${ }^{1}$, Ouma Onguka ${ }^{1}$, and Steven M. Claypool ${ }^{*}$ \\ Department of Physiology, Johns Hopkins University School of Medicine, Baltimore, MD, USA
}

\begin{abstract}
Phosphatidylethanolamine (PE) is the second most abundant glycerophospholipid in eukaryotic cells. The existence of four only partially redundant biochemical pathways that produce PE, highlights the importance of this essential phospholipid. The CDP-ethanolamine and phosphatidylserine decarboxylase pathways occur in different subcellular compartments and are the main sources of PE in cells. Mammalian development fails upon ablation of either pathway. Once made, PE has diverse cellular functions that include serving as a precursor for phosphatidylcholine and a substrate for important posttranslational modifications, influencing membrane topology, and promoting cell and organelle membrane fusion, oxidative phosphorylation, mitochondrial biogenesis, and autophagy. The importance of PE metabolism in mammalian health has recently emerged following its association with Alzheimer's disease, Parkinson's disease, nonalcoholic liver disease, and the virulence of certain pathogenic organisms.
\end{abstract}

\section{Introduction}

Phosphatidylethanolamine (PE) is a multifunctional phospholipid required for mammalian development that is essential for a variety of cellular processes. $\mathrm{PE}$ is a nonbilayer forming phospholipid containing a small polar head group diameter in proportion to its fatty-acid chains. The intrinsic biophysical properties of this cone-shaped lipid induces the formation of hexagonal phases within the membrane and, in so doing, promotes membrane fusion and fission events, protein integration into membranes, and conformational changes in protein structure (Dowhan and Bogdanov, 2009; van den Brink-van der Laan et al., 2004). PE is the second most abundant phospholipid in the cell, comprising 15-25\% of total phospholipids in mammalian cells (Vance, 2015). However, PE is not simply a passive membrane constituent but is functionally associated with protein biogenesis and activity (Becker et al., 2013; Bogdanov and Dowhan, 1995, 1998, 1999), oxidative phosphorylation (Bottinger et al., 2012; Tasseva et al., 2013), autophagy (Ichimura et al., 2000), membrane fusion (Verkleij et al., 1984), mitochondrial stability (Birner et al., 2001; Steenbergen et al., 2005; Storey et al., 2001), and is an important precursor of other lipids (Bremer and Greenberg, 1961; Menon and Stevens, 1992).

Four biosynthetic pathways produce PE in the cell, and notably, one of these pathways resides within the mitochondrion. The redundancy in PE biosynthetic pathways is not sufficient to allow for normal cellular function in the absence of either of the two major PE-

${ }^{*}$ Corresponding author. sclaypo1@jhmi.edu.

${ }^{1}$ Elizabeth Calzada and Ouma Onguka have contributed equally. 
producing pathways (Birner et al., 2001; Fullerton et al., 2007; Steenbergen et al., 2005; Storey et al., 2001). This suggests that different pools of PE are required for specified purposes in the cell. The abundance of PE varies in the membranes of different tissues and cells in mammals and organelles of both yeast and mammals (Bleijerveld et al., 2007; Colbeau et al., 1971; Nelson, 1967; Van Deenen and De Gier, 1974; Vance, 2015; Zinser et al., 1991). This review will focus on the numerous biological functions conferred by the intrinsic properties of PE. Recently, disturbances in PE metabolism have been implicated in both chronic and infectious disease (Chen et al., 2010; Deleault et al., 2012; Nesic et al., 2012; Wang et al., 2014). Phenotypic characterization of the cell biology of these diseases using a variety of model organisms collectively reveals a vital role for PE in mammalian health.

\section{Heterogeneity of Biological Membranes}

Biological membranes form the barriers that define cells and separate specified cellular functions into distinct but interconnected compartments. Beyond their ability to delineate different cell and organelle morphologies, cellular membranes are also multifunctional platforms involved in signaling, regulation of solute, metabolite, and protein transport; and are necessary mediums for proteins that require a hydrophobic environment for enzymatic function and stability. The wide range of biological processes mediated across membranes can be attributed to the mixture of proteins, lipids, and carbohydrates that concomitantly interact to give rise to specialized membrane environments. Greater than 1000 lipid species are present in the cell and over 30\% of an organism's translated genome is dedicated to the production of alpha helical membrane proteins (Stevens and Arkin, 2000; Sud et al., 2007). With respect to carbohydrates, there are innumerable structures, conformations, and combinations of sugars that can be formed in the cell, which further add to the diversity of the membrane environment.

The major classes of lipids in the cell include phospholipids, sterols, and sphingolipids. The rigidity, thickness, hydrophobicity, and function of cellular membranes are dependent upon the presence and relative abundance of these different classes of lipid. Glycerophospholipids, sterols, and sphingolipids comprise $\sim 75 \%, 12-14 \%$, and $8-12 \%$ of lipids in the cell, respectfully (Drin, 2014). Phospholipids are accountable for the formation of the membrane bilayer; the different classes of phospholipid in a membrane further modulate membrane identity and fluidity. Sterols, cholesterol in mammals, and ergosterol in yeast, decrease cell permeability by increasing membrane thickness and rigidity. Interestingly, the level of cholesterol is highest at the plasma membrane (20-40\%), moderate in the Golgi (8\%) and endoplasmic reticulum (ER) (6\%), and scarcely detected in mitochondria (4\%). The presence of sterols in conjunction with sphingolipids on the plasma membrane is important for cell-to-cell signaling events. As PE is the focus of this review, the biological importance of sterols and sphingolipids is beyond our scope but has been discussed in extensive detail in several fantastic reviews (Cowart and Obeid, 2007; Espenshade and Hughes, 2007; Futerman and Hannun, 2004; Hannun and Obeid, 2008; Mouritsen and Zuckermann, 2004; Ohvo-Rekila et al., 2002; Vance and Van den Bosch, 2000). 
Phospholipids are the predominant lipid components of most cellular membranes and are typically characterized by a glycerol backbone containing two ester linked fatty acid chains at the $s n-1$ and $s n-2$ positions and a phosphate head group at the $s n-3$ position (Figure 1; Van Deenen and De Gier, 1974). The head group attached at the $s n-3$ position distinguishes the different classes of phospholipid while subspecies of each phospholipid class also arise from differences in their acyl chain composition. The major glycerophospholipids in the cell include phosphatidylcholine (PC), PE, phosphatidylserine (PS), phosphatidylinositol (PI), phosphatidic acid (PA), phosphatidylglycerol (PG), and cardiolipin (CL). The distribution of each phospholipid can vary on different leaflets of the membrane bilayer, between organellar membranes, and by cell type and organism (Bretscher, 1972; Colbeau et al., 1971; Van Deenen and De Gier, 1974; Zinser et al., 1991). A typical mammalian cell contains approximately $45-55 \%$ PC, $15-25 \%$ PE, 10-15\% PI, 5-10\% PS, 2-5\% CL, and 1-2\% PA (Vance, 2015). PC is found equally distributed across cellular membranes while PS and PE are primarily found on the inner but not the outer leaflet of the plasma membrane. In addition, $\mathrm{PE}$ and $\mathrm{CL}$ are particularly abundant in the inner membrane of mitochondria (Vance, 2015). Further, CL is absent in other nonmitochondrial membranes of the cell. Enrichment of lipids in different corners of the cell can be attributed to numerous factors including their different sites of synthesis, interconversion, acyl chain remodeling, trafficking mechanisms, and degradation.

The ER is the primary site of synthesis for the majority of lipids in the cell. Many essential cell processes are sequestered in the ER, and as such, this organelle has compartmentalized some of these functions into distinct domains (Vance, 2014). Initial studies on the subcellular localization of phospholipid synthesizing enzymes localized them to microsomal fractions, but some microsomal vesicles containing high PS synthase activity were not enriched for the known ER-specific marker, NADPH-cytochrome- $c$ reductase (Dennis and Kennedy, 1972; van Golde et al., 1974; Zinser et al., 1991). Subsequently, the mitochondrial-associated membrane (MAM) of the ER was identified as a distinct site of lipid synthesis that harbors multiple phospholipid biosynthetic enzymes, including PS synthase, PI synthase, and PE methyl transferase (Cui et al., 1993; Gaigg et al., 1995; Vance, 1990). Additionally, the MAM is an important depot for the transport of substrates required for the biosynthesis of PE, PA, CDP-DAG, PG, and CL in mitochondria (transport mechanisms for PS and PE are covered in Sections 3.2.3 and 3.2.4) although CDP-DAG and PA can be synthesized in both the ER and mitochondria (Chen et al., 2006; Colbeau et al., 1971; Kuchler et al., 1986; Tamura et al., 2013; van Golde et al., 1974; Wirtz and Zilversmit, 1968; Yet et al., 1993).

\section{PE Biosynthesis and Metabolism}

There are four independent pathways by which PE is generated in eukaryotic cells (Figure 2). The CDP-ethanolamine pathway (Hjelmstad and Bell, 1991; Ishidate et al., 1985;

Mancini et al., 1999; van Hellemond et al., 1994; Wittenberg and Kornberg, 1953), acylation of lyso-PE (Riekhof et al., 2007b), and head group base exchange reactions (Dennis and Kennedy, 1972) are sequestered in the ER while the phosphatidylserine decarboxylase (Psd) pathway is largely specific to mitochondria (Borkenhagen et al., 1961; Horvath et al., 2012; Tamura et al., 2012b; Zborowski et al., 1983). While mammals have only one Psd enzyme 
that is localized in the mitochondrion, yeast have both the mitochondrially localized Psd1p (Horvath et al., 2012; Tamura et al., 2012b) and the endosome localized Psd2p (Gulshan et al., 2010; Trotter and Voelker, 1995). Of these two enzymes, Psd1p is the major source of cellular decarboxylase activity in yeast (Trotter et al., 1995). The predominant pathways for PE biosynthesis are the Psd and CDP-ethanolamine pathways (Birner et al., 2001); the other two ER pathways (acylation of lyso-PE and head group base exchange) weakly contribute to the cellular pool of PE (Sundler et al., 1974; Zelinski and Choy, 1982). While the CDPethanolamine pathway produces a species of PE that is enriched with mono-or diunsaturated fatty acids in the $s n-2$ position, the mitochondrial Psd pathway generates PE species with polyunsaturated fatty acids in the $s n-2$ position (Bleijerveld et al., 2007). However, the functional difference between PE produced by the Psd and the CDP-ethanolamine pathways is not clear although such a difference(s) is presumed based on the fact that each pathway is required for mammalian development (Fullerton et al., 2007; Steenbergen et al., 2005). Preference for either the Psd or CDP-ethanolamine pathway varies between organisms and tissues within metazoans although both pathways have been conserved from prokaryotes to eukaryotes (Dowhan et al., 1974; Miller and Kent, 1986; Tijburg et al., 1989). There are numerous fates of newly synthesized PE. It can be integrated into membranes at its site of synthesis, targeted to other cellular compartments, used as a precursor for the production of another essential phospholipid, PC, or utilized as a substrate for the production of basic posttranslational modifications such as glycosylphosphatidylinositol (GPI) anchors (Bremer and Greenberg, 1961; Menon and Stevens, 1992).

\subsection{ER Pathways}

There are three distinct PE biosynthetic pathways in the ER. While the major CDPethanolamine pathway is in the bulk ER, the head group base exchange and lyso-PE pathways reside in the MAM subcompartment of the ER that is in close physical proximity to the mitochondrion (Stone and Vance, 2000). The PE produced by these ER pathways gains access to membranes throughout the endomembrane system via the secretory pathway. As the mitochondrion is not part of this system, transfer of any phospholipid, including PE, from the ER to the mitochondrion must occur through other mechanisms that have substrate specificity (e.g., some phospholipids such as PC move quickly in both directions (de Kroon et al., 2003), whereas others, including PE, move in one direction better than the other (Birner et al., 2001; Burgermeister et al., 2004; Vance, 1991)).

3.1.1 Kennedy or CDP-Ethanolamine Pathway-The CDP-ethanolamine pathway resides within the ER and is the preferential pathway for PE biosynthesis in hamster heart and rat liver (Miller and Kent, 1986; Tijburg et al., 1989; Zelinski and Choy, 1982). The CDP-ethanolamine pathway consists of three enzymatic steps. The first step involves the ATP-dependent phosphorylation of ethanolamine by ethanolamine kinase to form phosphoethanolamine with ADP released as a byproduct (Lykidis et al., 2001). Mice in which ethanolamine kinase has been deleted have decreased litter size and about $20 \%$ die prenatally. Phosphoethanolamine can also be generated through the action of dihydrosphingosine-1-lyase (Dpl1p), which degrades sphingosine-1-phosphate producing phosphoethanolamine and a fatty aldehyde (Gottlieb et al., 1999; Zhou and Saba, 1998). The second step of the CDP-ethanolamine pathway, which is considered to be rate-limiting, is 
catalyzed by the protein product of the PCYT2 gene, CTP:phosphoethanolamine cytidylyltransferase (ET; Nakashima et al., 1997). ET uses phosphoethanolamine and CTP to form the high-energy donor CDP-ethanolamine with the release of inorganic phosphate. PCYT2 mRNA is highly expressed in the heart, liver, and skeletal muscle (Fullerton et al., 2007) tissues with high specific activities for these enzymes (Miller and Kent, 1986; Tijburg et al., 1989; Zelinski and Choy, 1982). Deletion of pcyt2 is embryonically lethal and although the heterozygotes appear normal (Fullerton et al., 2007), they experience metabolic defects as adults and during ageing (Fullerton et al., 2009). In the final step of PE synthesis by the CDP-ethanolamine pathway, 1,2-diacylglycerol ethanolamine phosphotransferase (ETP) utilizes the energy provided by CDP-ethanolamine to attach ethanolamine to the membrane-embedded diacylglycerol (DAG) thus forming PE (Lykidis et al., 2001; Sundler, 1975; Sundler and Akesson, 1975a; Tijburg et al., 1987).

The CDP-ethanolamine pathway is a major PE producing pathway in eukaryotes. Mammals and yeast lack the ability to produce ethanolamine, a substrate required for PE formation via the CDP-ethanolamine pathway, de novo. Ethanolamine used for PE synthesis derives from the breakdown of existing PE, exogenously added ethanolamine, and through the action of Dpl1p, which generates phosphoethanolamine from sphingosine-1-phosphate (Gottlieb et al., 1999; Zhou and Saba, 1998). In addition, mammals acquire ethanolamine through the diet usually in the form of lipids (Gottlieb et al., 1999).

3.1.2 Acylation of Lyso-PE and Head Group Exchange-PE can also be formed via acylation of lyso-PE (Jain et al., 2007; Riekhof and Voelker, 2006; Riekhof et al., 2007a,b; Tamaki et al., 2007) and calcium-dependent head group exchange with pre-existing phospholipids (Bjerve, 1984; Sundler et al., 1974); these two forms of PE synthesis are considered minor pathways of PE production. Lyso-PE is brought in through the exogenous lysophospholipid metabolism pathway. This pathway can utilize dietary lyso-PE that is first translocated across the plasma membrane and then acylated (Riekhof and Voelker, 2006). The uptake of lyso-PE is mediated by the plasma membrane aminophospholipid translocases Dnf1p and Dnf2p and their obligate partner, Lem3p (Riekhof et al., 2007a). Following its uptake, lyso-PE is converted to PE by Ale1p, an acyl-CoA-dependent acyltransferase (Jain et al., 2007; Riekhof et al., 2007b; Tamaki et al., 2007). Ale1p activity is enriched in the MAM; however, how lyso-PE traffics from its point of entry/ production to the MAM is not known. PE formed from the acylation of lyso-PE can substitute for the PE produced by the CDP-ethanolamine pathway and to some extent, the Psd pathway, as long as Ale1p is functional and lyso-PE is present (Riekhof et al., 2007b). Thus, the PE made by this minor pathway can access the same membrane compartments as normally supplied by the CDPethanolamine pathway. Also, the PE made by both of these ER-based pathways has a limited capacity to replace PE made in the mitochondrion (Tasseva et al., 2013).

\subsection{Mitochondrial Phosphatidylserine Decarboxylase (Psd) Pathway}

In contrast to the three aforementioned PE biosynthetic pathways, the second major route for PE production, the Psd pathway, resides in mitochondria. In the mitochondrion, PS decarboxylation to PE is performed by a single protein, Psd1p, that is embedded in the mitochondrial inner membrane (IM; Borkenhagen et al., 1961; Horvath et al., 2012; Tamura 
et al., 2012b; Trotter et al., 1993; Zborowski et al., 1983). Approximately $90 \%$ of PE in yeast cells is produced by Psd1p (Birner et al., 2001). The Psd pathway is also the major source of PE in baby hamster kidney and CHO1 cell lines in vitro (Miller and Kent, 1986; Voelker, 1984). In mammals, the Psd pathway is essential for viability since deletion of the gene encoding PSD1, PISD, is lethal between murine embryonic days 8 and 10 (Steenbergen et al., 2005). Although PISD ${ }^{-/+}$heterozygote brain, testes, and liver tissues have similar PE levels to wild type embryos, this reflects a compensatory increase in PE produced by the CDP-ethanolamine pathway. Still, this increase fails to substitute for the lack of mitochondrial PSD1 as evidenced by the embryonic lethality of $p_{i s d^{-1-}}$ mice. Consistent with the inability of the CDP-ethanolamine pathway to fully complement the mitochondrial need for PE, mitochondria in $p i s d^{-/-}$mouse embryonic fibroblasts are aberrantly shaped and fragmented (Steenbergen et al., 2005) and RNAi silencing of PISD in CHO1 cells impairs oxidative phosphorylation (Tasseva et al., 2013). Moreover, $p s d l \Delta$ yeast have numerous mitochondrial defects even though they retain the ability to synthesize PE via a second Psd enzyme (Psd2p), the CDP-ethanolamine pathway, and Ale1p (Birner et al., 2001; Storey et al., 2001; Trotter and Voelker, 1995). The failure of PE made in the ER to fully support mitochondrial functions in the absence of Psd1p likely reflects its inefficient trafficking into mitochondrial membranes (Birner et al., 2001; Burgermeister et al., 2004; Riekhof et al., 2007b; Shiao et al., 1995) although analysis of the acyl chain composition of PE by mass spectrometry has shown that PE species synthesized by the CDP-ethanolamine pathway are incorporated into the IM in mammalian cells (Bleijerveld et al., 2007; Kainu et al., 2013). Whether the acyl chain composition of PE affects mitochondrial function or if there is a required role in the mitochondrion for Psd1p independent of PE synthesis remain to be investigated.

3.2.1 Biogenesis of Phosphatidylserine Decarboxylase 1-Phosphatidylserine decarboxylase 1 (Psd1p) belongs to a family of decarboxylases that contain pyruvoyl prosthetic groups necessary for the decarboxylation of their substrate (van Poelje and Snell, 1990). PS decarboxylases and their role in phospholipid metabolism have been evolutionarily conserved from bacteria to humans (Schuiki and Daum, 2009). Yeast contain two Psd enzymes, the mitochondrial Psd1p (Clancey et al., 1993; Trotter et al., 1993) and Psd2p; Psd2p localizes to endosomes and is only a minor source of cellular PE (Birner et al., 2001; Gulshan et al., 2010; Trotter and Voelker, 1995). Importantly, the combined deletion of $P S D 1$ and $P S D 2$ produces a yeast strain that is auxotrophic for ethanolamine or lyso-PE, which allow PE to be produced by the CDP-ethanolamine pathway or through the reacylation of lyso-PE by Ale1p, respectively (Atkinson et al., 1980; Riekhof et al., 2007b).

The gene encoding Psd1p, PSDI in yeast or PISD in mammals, is nuclear-encoded and synthesized as a proenzyme by cytosolic ribosomes (Clancey et al., 1993; Kuge et al., 1991; Trotter et al., 1993). In yeast, Psd1p is targeted to the mitochondrial IM via its N-terminal mitochondrial targeting sequence. Upon its import into the IM, two matrix peptidases, matrix processing peptidase (MPP) and the octapeptidase, Oct1p, act to sequentially remove the mitochondrial targeting sequence (Horvath et al., 2012; Nebauer et al., 2007). A final autocatalytic processing step separates the enzyme into two subunits, $\alpha$ and $\beta$, generates a pyruvoyl prosthetic group at the $\mathrm{N}$-terminus of the smaller a subunit, and is required to 
generate an active enzyme (Choi et al., 2012, 2015; Dowhan et al., 1974; Horvath et al., 2012; Kuge et al., 1996; Li and Dowhan, 1988, 1990; Satre and Kennedy, 1978). The a subunit is anchored to the membrane by remaining noncovalently associated with the $\beta$ subunit that is integrated in the inner mitochondrial membrane facing the intermembrane space (IMS; Horvath et al., 2012; Li and Dowhan, 1988; Tamura et al., 2012b).

Pyruvoyl groups are not encoded by the genome and arise as a consequence of a posttranslational modification of the inactive proenzyme. The prosthetic group is a free carbonyl of pyruvate that is covalently linked to the modified protein (Satre and Kennedy, 1978). Studies on the biochemistry of autocatalytic processing in PS decarboxylases have mostly been done with bacterial Psd and show that following synthesis of the proenzyme, it undergoes an unusual processing event called nonhydrolytic serinolysis. Serinolysis not only separates the $\alpha$ and $\beta$ subunits but also additionally generates the pyruvoyl prosthetic group on the N-terminus of the a subunit. This processing event and the pyruvoyl group that it makes is essential for PS decarboxylation from bacteria to humans (Choi et al., 2012, 2015; Dowhan et al., 1974; Horvath et al., 2012; Kuge et al., 1996; Li and Dowhan, 1988, 1990; Onguka et al., 2015; Satre and Kennedy, 1978).

Interestingly, a catalytic triad typical of serine proteases is required for Psd1p autocatalysis (Choi et al., 2015). In addition to a conserved serine residue (Choi et al., 2012; Horvath et al., 2012; Kuge et al., 1996; Li and Dowhan, 1988), there are evolutionarily conserved aspartic acid and histidine residues that when individually mutated, prevent Psd1p autocatalysis (Choi et al., 2015). Consequently, prior to becoming a decarboxylase, Psd1p must first function as a serine protease. Yeast Psd1p redirected to the secretory pathway is autocatalytically competent, enzymatically active, and fully capable of supporting growth of $p s d 1 \Delta p s d 2 \Delta$ yeast in the absence of ethanolamine (Onguka et al., 2015). Thus, as long as it is anchored in a membrane, Psd1p itself contains everything else needed for autocatalysis and does not require the assistance of a mitochondrial-specific component.

3.2.2 PS Synthesis-In yeast and mammals, PS is synthesized in the MAM by phosphatidylserine synthase-1 (PSS1; Stone et al., 1998; Voelker, 1985). Mammalian cells also contain a second PS synthase enzyme, PSS2 (Stone and Vance 1999). PSS1 is ubiquitously expressed in all tissues and is enriched in brain and skeletal muscle (Nishijima et al., 1986; Sturbois-Balcerzak et al., 2001). Predominantly expressed in the testes, PSS2 is only a minor contributor of PS in other cell types (Bergo et al., 2002; Sturbois-Balcerzak et al., 2001). In yeast (and prokaryotes), PS is synthesized by the condensation of CDPdiacylglycerol and L-serine (Bae-Lee and Carman, 1984; DeChavigny et al., 1991). In contrast, mammals produce PS from a base-exchange reaction of L-serine with either PC or PE. PSS1 catalyzes a choline for serine head group exchange while PSS2 has been shown to have specificity for PE (Kuge et al., 1985; Suzuki and Kanfer, 1985). Overexpression of PSS1 but not PSS2 in rat hepatoma cells increases PS synthase activity suggesting that PSS1 activity is rate-limiting (Stone and Vance, 1999). Importantly, an increase in PS synthesis by PSS1 subsequently leads to an increase in the flux through the mitochondrial Psd pathway (Stone et al., 1998). Thus, the cell may harbor mechanisms to sense the relative ratio of phospholipids in different cellular membranes and respond in order to maintain this ratio. Alternatively, the increased flux through the Psd pathway could simply reflect an increase in 
substrate availability for PSD1 upon PSS1 overexpression. Deletion of PSS1 or PSS2 in mammals results in a compensatory increase of PS synthesis by the remaining enzyme (Arikketh et al., 2008; Borkenhagen et al., 1961). In a sss $^{2--}$ mouse model, the absence of PSS2 does not result in any changes in the PS/PE ratio across all tissues tested although some mice are infertile (Bergo et al., 2002). $p s s 1^{-/-}$mice have a slightly decreased PS/PE ratio in various tissues but for the most part the absence of PSS1 is compensated for by PSS2. However, simultaneous deletion of pss 1 and pss 2 is incompatible with life (Arikketh et al., 2008). This may be an indication of the fundamental importance of PS for cell function and viability. Or instead, it may reflect the subsequent importance of PS as a substrate for PE production via PSD1 whose ablation is also embryonically lethal (Steenbergen et al., 2005).

3.2.3 PS Transport-Since biosynthesis of PS occurs in the MAM of the ER and Psd1p is anchored to the IM with its catalytic site facing the IMS, biosynthesis of PE involves obligate inter- and intra-organellar lipid trafficking steps (Voelker, 1984). What is known about these transport processes is discussed next.

3.2.3.1. Into Mitochondria: The mechanistic details of how PS travels between ER and mitochondrial membranes remains to be fully characterized although this process has been heavily investigated in yeast and mammals (Achleitner et al., 1995; Daum et al., 1986; Hovius et al., 1992; Kuge et al., 1986; Vance, 1991; Voelker, 1984, 1985, 1989a,b, 1990; Wirtz and Zilversmit, 1968). It was postulated that transport of PS between MAM and the mitochondrial outer membrane (OM) could be mediated by vesicular transport, lipid carrier(s), or passive diffusion facilitated by proximal contact sites (Voelker, 1985, 1989b). Vesicular transport was presumed unlikely since mitochondria are not part of the classical secretory pathway. To test the involvement of lipid carriers, PS transport was analyzed in detergent solubilized cells, which effectively removes the cytosol. Results from this experimental paradigm indicate that in mammalian cells, the import of PS from MAM to the OM is an ATP-dependent process whereas PS transport in yeast does not require ATP (Achleitner et al., 1995; Daum et al., 1986; Voelker, 1985, 1989a,b, 1990). Collectively, these results strongly suggest that soluble lipid carriers are not required for ER to mitochondria PS transport (they would be removed with the bulk cytosol in detergent permeabilized cells) and that the mechanism of PS transport between these organelles has a different energetic requirement in mammals and yeast.

In contrast, there is an abundance of evidence to support contact-site facilitated transport of PS between the ER and mitochondria. The possibility that transport could utilize interorganelle contact sites was initially provided by electron micrographs, which showed regions in which the ER and mitochondria are closely juxtaposed $(\sim 30 \mathrm{~nm}$; Csordas et al., 2006; Mannella et al., 1998; Robertson, 1960). Subsequent studies identified MAM as an ER hub enriched in lipid-synthesizing enzymes (e.g., PSS1) whose presence is important for the mitochondrial synthesis of PE (Vance, 1990). In yeast, a physical multiprotein complex termed the ER-mitochondria encounter structure (ERMES) bridges the small space between these organelles at proximal junctions (Kornmann et al., 2009). ERMES is composed of a complex of proteins that includes the outer mitochondrial membrane proteins, Mdm10p 
(Meisinger et al., 2004; Sogo and Yaffe, 1994) and Mdm34p (Dimmer et al., 2002; Youngman et al., 2004), an ER-membrane protein, Mmm1p (Burgess et al., 1994; Kornmann et al., 2009), and cytosolic Mdm12p (Berger et al., 1997; Kornmann et al., 2009). Furthermore, the ERMES complex is regulated by Gem1p, a mitochondrial GTPase (Kornmann et al., 2011). Although disruption of ERMES components decreases the number of contact sites between the ER and mitochondria and results in aberrant mitochondrial morphology (Berger et al., 1997; Burgess et al., 1994; Dimmer et al., 2002; Sogo and Yaffe, 1994; Youngman et al., 2004), the cellular and mitochondrial levels of PE in the cell is unaffected in its absence (Kornmann et al., 2009; Nguyen et al., 2012). However, there is an increase in cellular and mitochondrial PS in ERMES mutants (Tamura et al., 2012a). Beyond its function as an interorganelle tether, it is unclear if the ERMES complex has a direct biochemical role in translocating PS from the MAM to the mitochondrial OM (Nguyen et al., 2012; Voss et al., 2012). Indeed, the ERMES complex can be replaced by the synthetic ER-mitochondria tether, ChiMERA, which restores the phenotypic consequences that result when the ERMES complex is missing (Kornmann et al., 2009; Nguyen et al., 2012).

Recent evidence has shown that a second protein complex named the ER-membrane protein complex (EMC) contributes to phospholipid transfer between mitochondrial and ER membranes and importantly, is conserved across species (Lahiri et al., 2014). The EMC is composed of six different proteins, Emc1-6p. Localization of EMC proteins across ER membranes is dispersed as opposed to forming clear puncta as expected for a protein tether. Deletion of a single protein within the complex is not sufficient to disrupt ER-mitochondria contact site formation, and a decrease in PE synthesis is only observed upon the combinatorial deletion of multiple EMC subunits. Deletion of the EMC is synthetically lethal with the absence of the ERMES complex, suggesting that these two ER-mitochondria tethers serve overlapping essential roles in maintaining cellular and mitochondrial function. Although a marked decrease in PE synthesis by Psd1p occurs in the absence of the EMC, such production can be rescued by expression of the synthetic tether CHiMERA suggesting that like ERMES, EMC has no direct biochemical role in phospholipid transport and may simply function as a biological tether between organelles. The EMC associates with a component of the translocase of the outer membrane, Tom5p; however, as PS transport into the $\mathrm{OM}$ is normal in tom $5 \Delta$ yeast, other mitochondrial factors must also be involved in bridging this interaction (Lahiri et al., 2014).

Orthologs of ERMES-like proteins have yet to be identified in mammals although contact site formation is still observed. Further, whether the conserved EMC functions in a similar manner in mammals as in yeast has not been determined. However, numerous other proteins are enriched at ER-mitochondria junctions in mammals that may collectively serve redundant functions linking these two organelles. These candidate ER-mitochondria tethers include GTPases and proteins with roles in regulating mitochondrial morphology. Mitofusin 2 (MFN2), a mitochondrial dynamin-related GTPase, forms ER-mitochondria tethers by virtue of an ER-localized MFN2 in a homo- or heterotypic complex with MFN2 or MFN1 on the outer membrane of mitochondria, respectfully (de Brito and Scorrano, 2008). Phosphofurin acid cluster sorting-protein (PACS-2) is a multifunctional protein that is 
important for organelle morphology, apoptotic signaling, ER homeostasis, and calcium signaling. PACS-2 depletion causes mitochondrial fragmentation, dissociates ER from mitochondria, and decreases the level of PSS1 present in MAM (Simmen et al., 2005). Voltage-dependent anion channels (VDAC) are outer membrane proteins that allow the passive diffusion of small molecules and metabolites across the outer membrane (Rapizzi et al., 2002) and which accumulate in regions of close apposition between mitochondria and ER (Garcia-Perez et al., 2011; Shoshan-Barmatz et al., 2004). As mitochondria buffer calcium released by the ER (Hajnoczky and Thomas, 1997), known and proposed proteins that promote contact sites with mitochondria are associated with decreased calcium signaling in their absence. Indeed, the selectivity of the VDAC channel is modified through its interaction with the molecular chaperone glucose-regulated protein 75 (GRP75), which links VDAC to the ER calcium-release channel inositol 1,4,5-trisphosphate receptor $\left(\mathrm{IP}_{3} \mathrm{R}\right)$ in HeLa cells (Szabadkai et al., 2006). As both VDAC and $\mathrm{IP}_{3} \mathrm{R}$ coimmunoprecipitated with GRP75, but not with each other, GRP75 forms a bridge that juxtaposes ER-based calcium release with mitochondria thus supporting the latter organelle's calcium buffering capacity. Consistent with the notion of tethering redundancy, knock down of MFN2 in HeLa cells does not diminish PS import to mitochondria or PE synthesis via the Psd pathway as measured by mass spectrometry (Kainu et al., 2013). Clearly, the mechanism of PS transport between the ER and mitochondria remains nebulous.

Lipid trafficking in and out of mitochondria is expected to be critical for cell viability. Since the ERMES complex is nonessential (Kornmann et al., 2009; Nguyen et al., 2012; Tamura et al., 2012a; Voss et al., 2012), the possibility of an alternative pathway for PS import was suggested. Recently, a yeast vacuole-mitochondria tether termed v-CLAMP was shown to be essential for cell survival in the absence of ERMES components (Elbaz-Alon et al., 2014; Honscher et al., 2014). In the absence of the ERMES complex, vacuoles surround mitochondria and the contacts between these two organelles increase. When v-CLAMP expression is repressed in a yeast background unable to form ERMES complexes, PE levels and synthesis are significantly reduced (Elbaz-Alon et al., 2014). The extent of mitochondria- vacuole contacts versus ER-mitochondria contacts varies depending on the available carbon source; ERMES-mediated ER-mitochondria contacts dominate in nonfermentative media whereas mitochondria-vacuole contacts generated by v-CLAMP predominate in fermentable media (Honscher et al., 2014). The synthetic lethality between ERMES and v-CLAMP demonstrates the obligate need of mitochondria to obtain lipid precursors from neighboring organelles for the biosynthesis of PE (and CL) as well as the acquisition of phospholipids not made in the cell's powerhouse.

3.2.3.2. Within Mitochondria: In mammals, dinitrophenol but not carbonyl cyanide $m$ chlorophenyl hydrazone inhibits PS import from the OM to the IM (Hovius et al., 1992). Since both compounds are uncouplers that disrupt oxidative phosphorylation, this suggests that dinitrophenol impairs PS uptake by either disturbing IM/OM contacts or increasing the distance between these two membranes (Knoll and Brdiczka, 1983). Similarly, PS import from the OM to the IM in yeast is ATP-independent and does not require either a functional membrane potential or oxidative phosphorylation machinery (Achleitner et al., 1995, 1999; Gnamusch et al., 1992). Akin to the numerous tethers between the outer membrane and 
other organelles, there is an IM/OM scaffold termed the mitochondrial contact site and cristae organizing system (MICOS); this scaffold is also crucial for cristae junction formation (Alkhaja et al., 2012; Harner et al., 2011; Hoppins et al., 2011; Itoh et al., 2013; Jans et al., 2013; von der Malsburg et al., 2011). MICOS is a hetero-oligomeric protein complex that is conserved from yeast to mammals and is important for mitochondrial biogenesis, morphology, and inheritance. Whether transport of PS between OM and IM leaflets utilizes MICOS-based IM/OM scaffolds has yet to be elucidated.

Lipid carriers may also be involved in shuttling incoming PS to the IM although a potential PS carrier has not been identified. The role of the Ups family of proteins (Ups1-3p) in mitochondrial phospholipid metabolism has been investigated and evidence supports their involvement in both PE and CL synthesis (Osman et al., 2009; Potting et al., 2010; Tamura et al., 2009). The unique dimeric phospholipid CL is specific to mitochondrial and bacterial membranes. In eukaryotes, CL biosynthesis requires that its substrate PA is trafficked to the matrix side of the IM (Schlame and Haldar, 1993). Ups (unprocessed) proteins are putative lipid carriers that were identified in yeast and are homologous with the mammalian MSF1/ PRELI protein families (Sesaki et al., 2006). The stability of Ups proteins within the intermembrane space is dependent upon their productive association with the IMS protein Mdm35p (Potting et al., 2010; Tamura et al., 2010). As the Ups1p/Mdm35p complex transports PA across the IMS, deletion of UPS1 results in a decrease in CL (Connerth et al., 2012; Potting et al., 2013; Tamura et al., 2009). Interestingly, UPS2 deletion in ups $1 \Delta$ yeast prevents the decrease in CL (Tamura et al., 2009). Further, overexpression of Ups2p results in a decrease in CL suggesting that it regulates Ups1p function (Osman et al., 2009). In addition to their antagonistic roles in CL metabolism, the absence of Ups2p results in a decrease in PE that is associated with a faster rate of PE to PC conversion (Tamura et al., 2012a). As such, Ups1p is suggested to accelerate export of PE from mitochondria and increase its subsequent conversion to PC in the MAM. In turn, the presence of Ups2p somehow regulates this process. The exact role of Ups1p and Ups2p in PE synthesis and export is presently unclear as is the molecular function of Ups3p, whose deletion does not alter mitochondrial phospholipid profiles (Tamura et al., 2009).

Given its lack of known energy requirements, the directionality of PS transport is likely provided through its conversion to PE by Psd1p in the inner membrane. The capacity to import phospholipids irrespective of mitochondrial function may allow for maintenance of mitochondrial membranes in situations where oxidative phosphorylation is disrupted. If the oxidative phosphorylation dysfunction is secondary to defects in its membranes, then this could allow the membranes to be repaired thus restoring mitochondrial energy production.

3.2.4 Fate of PE Produced by Psd1p-PE produced by Psd1p in the context of the IMS-leaflet of the IM has at least two fates. It can either stay in mitochondria (associated with the IM or OM) and support mitochondrial functions therein (discussed in Section 4.3). Or alternatively, it can exit mitochondria and contribute to the cellular pool of PE and lipid derivatives of PE. PE export from mitochondria is stimulated in cases where substrates for PE production via the CDP-ethanolamine pathway are lacking (Kainu et al., 2013). In contrast, robust levels of PE in ER membranes discourage PE export as this process may be more energetically unfavorable. Shuttling of PE from the IM to other parts of the cell is an 
additional phospholipid trafficking process that remains poorly characterized. As previously mentioned, the absence of Ups2p in yeast results in a decrease in mitochondrial PE suggesting that Ups1p plays a role in expediting PE export from the IM. Presumably, Ups2p regulates this export. However, in the absence of Ups1p, no accumulation of PE is observed (Osman et al., 2009; Tamura et al., 2012a). The role of inter- and intraorganelle contact sites or additional mitochondrial lipid carriers needs to be interrogated in this process.

\subsection{PE as Precursor for Other Lipids and Substrate for Posttranslational Modifications}

The cell is a sophisticated factory of proteins, lipids, and carbohydrates where each of these components can be modified or recycled to accommodate the cell's metabolic state. An interesting aspect of lipid biology is that phospholipids can be interconverted between distinct classes. For example, PE produced by the mitochondrial Psd pathway derives from the decarboxylation of PS. Further, PE produced by either the CDP-ethanolamine or decarboxylation pathways can be converted to PC (Kennedy and Weiss, 1956; Ridgway and Vance, 1987). PE is also a critical substrate for at least two fundamental posttranslational modifications, GPI anchors (discussed later; Menon and Stevens, 1992; Wilson-Zbinden et al., 2015) and lipidation of Atg8p/LC-3 (discussed in Section 4.4; Ichimura et al., 2000).

3.3.1 Methylation of PE to Form PC-Constituting 40-50\% of total phospholipids in most organelles, phosphatidylcholine is the most abundant phospholipid in eukaryotes (Vance, 2015). PC has a cylindrical shape in which its phospholipid head group and fatty acyl tails are of equal diameter. This property allows PC to become tightly packed within the membrane, which promotes the formation of membrane bilayers.PC is predominantly produced by the CDP-choline pathway, where CDP-choline condenses with a DAG moiety to generate PC (Kennedy and Weiss, 1956). However, a minor pathway involving trimethylation of PE to PC also exists and can account for 20-30\% of PC in liver cells (Sundler and Akesson, 1975b). PC made by this pathway, which is performed in the MAM (Cui et al., 1993; Vance, 1990), can utilize PE produced by any of the four routes of PE biosynthesis. A single enzyme is responsible for PC synthesis from PE in mammals, PE Nmethyl transferase (PEMT), while yeast contains two enzymes, PE methyltransferase (Pem1p) and phospholipid methyltransferase (Pem2p). PE undergoes three successive methylation reactions by PEMT for its full conversion to PC (Ridgway and Vance, 1987). In yeast, Pem1p converts PE to phosphatidyl- $N$-monomethylethanolamine (PMME) in the first methylation reaction; Pem2p has a low affinity for this reaction as well. Pem2p then successively methylates PMME to phosphatidyl- $N, N$-dimethylethanolamine (PDME) and PDME to PC (Kodaki and Yamashita, 1987).

\subsubsection{Phosphoethanolamine for GPI Anchor Formation-GPI anchoring is a} posttranslational modification that is conserved among all eukaryotes. A GPI anchor is a glycolipid structure that is added posttranslationally to the C-terminus of many eukaryotic proteins. GPIs are synthesized in the ER by at least 10 enzymes and up to 20 genes are involved (Fujita and Kinoshita, 2010; Kinoshita et al., 2008). GPI biogenesis is essential for embryogenesis (Nozaki et al., 1999), neurogenesis (Ueda et al., 2007), immune responses, and fertility (Ueda et al., 2007). GPI-anchored proteins selectively associate with lipid rafts, membrane domains that serve as platforms for signaling and protein trafficking. Proteins 
that are linked to the plasma membrane by GPI anchors can remain thusly associated or are instead cleaved and released from the membrane.

The GPI core consists of phosphatidylinositol, a glucosamine moiety, three mannoses, and phosphoethanolamine (Ferguson, 1999; Ikezawa, 2002; Nosjean et al., 1997). A complete GPI precursor is transferred to proteins containing a GPI anchor signal sequence at the Cterminus. GPI anchors form on the lumenal side of the ER where a glycan core is assembled from a complex of mannose residues linked to the inositol head group of PI. A phosphoethanolamine linker is then attached to the C-terminus of the target protein and a mannose residue of the glycan core, which anchors the protein to the ER membrane facing the lumen (Kinoshita et al., 2008). PE provides the ethanolamine group used to make the phosphoethanolamine bridge between the glycan and C-terminal amino acid of the GPIanchored protein (Menon and Stevens, 1992). There are three proteins involved in transferring additional phosphoethanolamine groups to mannose residues on newly formed GPI anchors. The first mannose residue is modified by Mcd4p in yeast and PIG-N in mammals, which localize to the ER (Gaynor et al., 1999; Hong et al., 1999). Deletion of MCD4 is lethal in yeast as GPI anchor biosynthesis is critical for cell wall integrity (Gaynor et al., 1999). Addition of phosphoethanolamine to mannose 2 and 3 is carried out by Gpi7p and the protein product of yeast YLL031C (PIG-O in mammals), respectively (Flury et al., 2000). As GPI-anchor formation is a multistep process, defects and/or mutations that impair any of a number of its intermediate reactions, including formation of the phosphoethanolamine bridge, can cause disease (Maydan et al., 2011; Takeda et al., 1993). The impact of PE depletion on GPI anchor formation and its potential relevance to Parkinson's disease is discussed in Section 5.2.

\section{Cellular and Molecular Functions of PE}

The existence of multiple PE-producing pathways combined with the absolute requirement of both the CDP-ethanolamine pathway in the ER and the Psd pathway in the mitochondrion for mammalian development highlights the importance of PE in performing specified functions in the cell (Fullerton et al., 2007; Steenbergen et al., 2005). As a nonbilayer forming phospholipid, a high PE content in cellular membranes promotes the formation of hexagonal phase structures, which antagonize the tight packing of membrane bilayer forming phospholipids such as PC (Osman et al., 2011). Hexagonal phase structures in the membrane have been shown to induce bilateral membrane stress that can be relieved by membrane bending events, protein insertion at sites containing poor membrane packing, or conformational changes within membrane proteins that rearrange the lipid distribution (van den Brink-van der Laan et al., 2004). It is no surprise then that PE associates with and modulates the behavior of a variety of proteins and protein complexes with diverse roles in a range of cellular processes.

\subsection{PE as a Determinant of Protein Topology}

The final topology of membrane proteins is determined by several intrinsic features including the presence of hydrophobic alpha helical stretches, which are often flanked by charged amino acid residues. Of particular importance are flanking positively charged residues, which orient a membrane anchor such that these reside in the cytosol (the positive- 
inside rule; Nilsson and von Heijne, 1990). In addition to such intrinsic topological information, the presence or absence of certain phospholipids in a membrane can interact with membrane proteins and introduce dynamic or steady state effects on its topology, structure, and function (Bogdanov et al., 2002, 2009; DeChavigny et al., 1991; Seto-Young et al., 1985). One such lipid is PE (Bogdanov and Dowhan, 1995). Importantly, the topologies that are sensitive to PE can be reversible (occur post-biosynthesis and membrane integration) and switch the membrane protein between active and inactive states (Bogdanov and Dowhan, 1998, 1999; Bogdanov et al., 2002). Work in bacteria and in reconstituted liposomes demonstrated that PE is required for energy-dependent uphill substrate accumulation but not energy-independent downhill substrate equilibration mediated by lactose permease (LacY; Bogdanov and Dowhan, 1995). The lack of PE induces topological inversion of the N-terminal six transmembrane (TM) domains of LacY, exposure of the seventh TM domain to the periplasm, and misfolding of a periplasmically exposed domain (Bogdanov et al., 2008); proper folding of this domain is linked to the ability of LacY to mediate secondary active transport (Bogdanov and Dowhan, 1999).

Interestingly, if PE is made after LacY is improperly membrane-integrated, the seventh TM domain in the periplasm reinserts across the membrane, which causes the preceding four TM domains to change their topology; the first TM domain remains in the opposite orientation as observed when PE is present during the biogenesis of $\mathrm{LacY}$ while the second TM domain adopts an interfacial conformation that goes into but not through the membrane (Bogdanov et al., 2008; Zhang et al., 2003). All of these changes induced by PE on existing LacY restore its ability to utilize a proton gradient to transport sugars uphill. How does PE have such a major impact? Presently, it is speculated that uncharged phospholipids such as PE shield negatively charged amino acid residues adjacent to TM domains (Bogdanov et al., 2008 , 2014). This both diminishes their potential to serve as topological determinants and increases the strength of surrounding positively charged amino acids to act in this capacity. In the absence of PE, negatively charged TM-flanking residues regain topogenic strength. If revealed in the context of TM domains that are not very hydrophobic, such as TM domain 7 of LacY, this can provoke significant topological changes with functional consequences.

The importance of PE in topological orientation has also been determined for other bacterial transporters, including the $12 \mathrm{TM}$ domain-containing phenylalanine and $\gamma$-aminobutyrate permeases (Bogdanov et al., 2008; Zhang et al., 2003, 2005). The ability of PE to influence the topology and function of eukaryotic proteins has not been demonstrated. Still, these elegant studies in bacteria suggest that this mode of regulation may be relevant in eukaryotic cells especially since many organelles are ensheathed by membranes of distinct lipid compositions.

\subsection{Membrane Fusion}

During the late stages of cell division, daughter cells separate into individual cells at cytokinesis. The contractile ring marks the boundary to separate the dividing cell and is composed of actin filaments that create tension at the plasma membrane to promote fusion (Schroeder, 1990). This generates what is widely known as the "cleavage furrow" at the membrane of the dividing cell, which becomes more pronounced and fuses at the end of 
telophase creating two individual daughter cells. PE, which is normally enriched on the inner leaflet of the plasma membrane, accumulates on the external leaflet specifically at the cleavage furrow during a late stage of telophase (Emoto et al., 1996). Interestingly, a streptavidin-conjugated fluorescent probe that specifically binds to PE inhibits cytokinesis at telophase by trapping PE on the external surface. Importantly, the block in cytokinesis is reversed by incubating cells with PE-loaded liposomes (Emoto and Umeda, 2000). Further, a cell line defective in the mitochondrial Psd pathway of PE biosynthesis has a defect in cytokinesis that is rescued if provided supplemental PE or ethanolamine, the latter of which stimulates PE production via the CDP-ethanolamine pathway. Mechanistically, retention of PE on the cell surface does not disturb the formation of cytoskeletal components (microtubules and actin) important for cytokinesis, membrane furrowing, or separation of chromosomes but does prevent actin filament disassembly and membrane fusion (Emoto and Umeda, 2000). Thus, the transient surface appearance of PE along the cleavage furrow and its subsequent reinternalization to the inner leaflet of the plasma membrane are temporally regulated events that are of fundamental importance at a late stage in cell division. Moreover, PE produced by either the Psd or CDP-ethanolamine pathways can fulfill this cellular function.

Additionally, PE has a pivotal role in the fusion of Golgi membranes that occurs after cell division. Fusion of Golgi membranes involves the association of cytosolic factors with components of the Golgi membrane fusion machinery. During vesicle fusion, p97, a cytosolic ATPase of the fusion machinery, associates with the t-SNARE associated factor, p47 (Otter-Nilsson et al., 1999). The activity of the p97/p47 complex, which is sufficient for mediating fusion, is influenced by the presence of PE in Golgi membranes. PE increases the head group spacing between lipids present in Golgi membranes allowing conformational changes that are required for membrane fusion to be induced within the p97/p47 complex (Pecheur et al., 2002).

\subsection{PE in Mitochondrial Function}

CL and PE make up about 35-50\% of the total phospholipids within the mitochondrial inner membrane (Daum, 1985). CL is a dimeric phospholipid that contains two phosphatidic acids bridged by a glycerol group and four fatty acyl chains. Mitochondria are the sole manufacturers of CL in eukaryotic cells and generate CL on the matrix-side of the IM (Baile et al., 2014; Claypool and Koehler, 2012; Schlame and Haldar, 1993). Ablating mitochondrial PE ( $p s d 1 \Delta$ ) or CL ( $c r d 1 \Delta ; C R D l$ encodes cardiolipin synthase) biosynthesis in yeast yields viable cells (Chang et al., 1998; Clancey et al., 1993; Jiang et al., 1997; Trotter et al., 1993; Tuller et al., 1998). psd $1 \Delta$ and $c r d l \Delta$ yeast share several phenotypes including reduced growth in nonfermentable carbon sources, increased frequency of petite formation (the mitochondrial genome is absent or defective), and sensitivity to increased temperature (Birner et al., 2001; Jiang et al., 1997; Storey et al., 2001; Zhong et al., 2004). While the single mutants are viable, the combined $\operatorname{crd} 1 \Delta p s d 1 \Delta$ mutant is not (Gohil et al., 2005). Only deletion of $P S D 1$, and not the CDP-ethanolamine pathway or PSD2, is synthetically lethal with $\operatorname{crd} 1 \Delta$ (Gohil et al., 2005). This likely reflects the fact that PE produced by either of these pathways is poorly integrated in mitochondrial membranes 
(Birner et al., 2001; Burgermeister et al., 2004) and that the pool of PE in the IM of mitochondria is predominantly produced by Psd1p (Shiao et al., 1995).

In the membranes of prokaryotic cells, which lack PC but are enriched in both PE and CL, the absence of PE results in a compensatory increase in CL (Rietveld et al., 1993). This reciprocal relationship is also observed in yeast when pools of PE or CL are depleted through deletion of genes involved in their biosynthesis and/or regulation (Osman et al., 2009; Zhong et al., 2004). psdl $\Delta$ and $c r d 1 \Delta$ yeast also share synthetic genetic interactions with genes that encode similar mitochondrial proteins; namely the prohibitin lipid scaffolds and the lipid transport proteins, Ups1p and Ups2p (Hoppins et al., 2011; Kornmann et al., 2009; Osman et al., 2009). Thus, PE and CL have converging functions in mitochondria that collectively highlight their individual and combined importance for mitochondrial function (Gohil et al., 2005). The specific roles that CL plays in mitochondrial biology, health, and disease merits more detailed attention, which has been provided by several excellent reviews (Claypool and Koehler, 2012; Joshi et al., 2009; Lu and Claypool, 2015; Schlame and Ren, 2009).

4.3.1 Oxidative Phosphorylation- $p s d l \Delta$ yeast have impaired growth and increased petite formation when grown in respiratory media, characteristic of yeast with disrupted oxidative phosphorylation capacities (Birner et al., 2001). When mitochondrial PE production is reduced in CHO-K1 cell lines by RNAi inhibition of the mammalian PISD gene, mitochondrial membrane potential is increased, complex I and complex IV activity of the respiratory chain is reduced, and ATP production is significantly decreased (Tasseva et al., 2013). Individual electron transport chain complexes assemble in higher order structures known as supercomplexes (Cruciat et al., 2000; Schagger and Pfeiffer, 2000). Supercomplex formation of the different electron transport chain components maximizes respiratory capacity in mitochondria (Acín-Pérez et al., 2008; Lapuente-Brun et al., 2013). The role of $\mathrm{PE}$ in supercomplex formation is species-specific as results between yeast and mammals differ. In mammals, depletion of mitochondrial PE disrupts the formation of higher order complexes associated with complex IV (Tasseva et al., 2013). In contrast, in yeast, supercomplexes between respiratory complexes III and IV (yeast lack complex I) are stabilized in the absence of PE (Bottinger et al., 2012). While the impact of PE on supercomplex stability is different, its absence in yeast and mammals alike decreases respiratory function.

Cytochrome $c$ oxidase (complex IV) oxidizes reduced cytochrome $c$ by reducing divalent oxygen to water. The crystal structure of complex IV from bovine heart shows that there are three PE monomers associated with different components of this respiratory complex (Shinzawa-Itoh et al., 2007). Importantly, two PE monomers are at the interface where complex IV dimerizes. InpsdI $1 \Delta$ yeast, complex IV activity is significantly decreased (Bottinger et al., 2012). This suggests that PE plays an indispensable and unique role in complex IV activity. Interestingly, even though ubiquinol: cytochrome $c$ oxidoreductase (complex III) from yeast cocrystallizes with PE (Lange et al., 2001), complex III function is normal in $p s d l \Delta$ yeast (Bottinger et al., 2012). 
An interesting role for PE in hepatocyte mitochondrial membranes has been proposed for glucose metabolism and oxidative phosphorylation in mice. As previously mentioned, about $20-30 \%$ of PC in hepatocytes is made by the trimethylation of PE to PC (Sundler and Akesson, 1975b). pemt ${ }^{-1-}$ mice are protected against insulin resistance when supplemented with a high fat diet (more on the characteristics of $\mathrm{pemt}^{-/-}$mice in Section 5.3; van der Veen et al., 2014). Elimination of PE methylation increases mitochondrial PE levels as well as pyruvate flux through the tricarboxylic acid cycle for ATP production. Abolishing PEMT did not affect the enzymatic activity of proteins involved in gluconeogenesis, but nonetheless mice were protected against insulin resistance. Instead, PEMT ablation appears to lower hepatic glucose production by increasing the activity of the electron transport chain. This increase in respiratory function correlates with a decrease in the mitochondrial PC:PE ratio (van der Veen et al., 2014). The increase in hepatocyte mitochondrial PE levels in pemt $t^{-/}$mice indicates that the mitochondrial Psd pathway is an important source of PE used by PEMT, at least in the liver. Whether and how the altered mitochondrial PC:PE ratio causes the observed changes in mitochondrial substrate utilization is unclear. In sum, these results suggest that in the liver, this dynamic pathway of PC production utilizes PE made in mitochondria, is important for normal hepatocyte physiology, and potentially, whole-body glucose homeostasis.

4.3.2 Mitochondrial Protein Biogenesis and Activity-Mitochondrial protein import at the OM and IM is defective when PE is limiting. The import of preproteins into and across the IM through the translocases of the inner membrane (TIM) complexes (TIM23 and TIM22) is driven by the electrochemical gradient across the IM, which is generated by the respiratory chain and reduced in $p s d 1 \Delta$ and $p s d l \Delta p s d 2 \Delta$ yeast (Bottinger et al., 2012; Chacinska et al., 2009). Thus, the defect in IM biogenesis in $p s d 1 \Delta$ and $p s d 1 \Delta p s d 2 \Delta$ yeast is secondary to a decrease in the functionality of the respiratory chain. PE is additionally important for the biogenesis of $\beta$-barrel proteins of the mitochondrial OM (Becker et al., 2013). Biogenesis of $\beta$-barrel proteins begins with specific recognition of the imported precursor by the translocase of the outer membrane (TOM) translocon (Chacinska et al., 2009). Next, $\beta$-barrel precursors are translocated into the IMS before being passed to the sorting and assembly machinery (SAM) complex in a process that requires the small TIM complexes, IMS resident chaperones. Proper membrane insertion and folding of $\beta$-barrel proteins is mediated by the SAM complex. In $p s d 1 \Delta$ and $p s d 1 \Delta p s d 2 \Delta$ yeast, biogenesis of $\beta$ barrel proteins is impaired early in the process and at multiple steps (Becker et al., 2013). First, precursor binding by the TOM complex is reduced in the absence of normal levels of mitochondrial PE. And second, translocation of $\beta$-barrel precursors through the TOM complex into the IMS, as determined by resistance to protease digestion, is also reduced in $p s d 1 \Delta$ and $p s d 1 \Delta p s d 2 \Delta$ yeast. Interestingly, this decrease in activity is independent of the stability of the TOM complex since assembly by blue-native PAGE electrophoresis and protein-protein interactions by coimmunoprecipitation show that the TOM complex remains intact (Becker et al., 2013). Additionally, this defect is specific for $\beta$-barrel proteins, as the biogenesis of alpha helical OM proteins is not influenced by the presence or absence or PE.

4.3.3 Mitochondrial Fusion-Mitochondria are dynamic organelles that frequently fuse and divide to maintain their function and morphology (Friedman and Nunnari, 2014; van der 
Bliek et al., 2013). Mitochondrial fission and fusion is mediated by members of the dynamin-like GTPase protein family. Fission is dependent on DRP1 (Dnm1p in yeast; Bleazard et al., 1999; Smirnova et al., 2001). OM fusion is executed by the mitofusins (MFN1 and MFN2 in mammals and Fzo1p in yeast; Chen et al., 2003; Hermann et al., 1998; Santel and Fuller, 2001) and IM fusion involves OPA1 in mammals and Mgm1p in yeast (Alexander et al., 2000; Delettre et al., 2000; Jones and Fangman, 1992). OPA1 and Mgm1p are processed into long and short forms that differ with respect to their membrane association and which are both required for IM fusion (Griparic et al., 2007; Song et al., 2007; Zick et al., 2009). Fragmented and aggregated mitochondria accumulate in $p s d 1 \Delta$ yeast, which also have a skewed long:short Mgm1p ratio (less short than normal; Chan and McQuibban, 2012; Osman et al., 2009). This suggests that PE produced by Psd1p influences the production of short Mgm1p likely at an ATP-dependent step that is required upstream of its cleavage by the rhomboid protease, Pcp1p (Herlan et al., 2003, 2004; McQuibban et al., 2003). In addition to the involvement of these GTPases in mitochondrial fission and fusion, the biophysical properties of certain lipids, including PE, may also influence these dynamic processes. In vitro fusion experiments using protein-free liposomes that mimic mitochondrial membranes with reduced PE levels have decreased rates of lipid mixing postfusion, which could decrease the efficiency of this process (Chan and McQuibban, 2012). When CL levels become limiting in $p s d 1 \Delta$ yeast, the membrane potential is reduced, mitochondrial DNA is lost, expression of Mgm1p (long and short) is reduced, and mitochondria become highly fragmented (Joshi et al., 2012). These results suggest that PE has an important role in mitochondrial fusion that becomes essential in the absence of CL.

\subsection{Autophagy}

Autophagy is an important catabolic process that recycles cytosolic proteins and membranes through their degradation within lytic compartments in the cell (lysosomes in mammals or vacuoles in yeast; Mizushima et al., 2011; Ohsumi, 2014). Macroautophagy (for other forms of autophagy please refer to Mizushima et al. (2011); Reggiori and Klionsky (2013)) involves formation of the autophagosome, a double membrane-bound structure that encases cargo destined for degradation and delivers it to the lysosome/ vacoule (Tooze and Yoshimori, 2010). Autophagosome biogenesis begins with the formation of a cup-like membrane sac referred to as the isolation membrane or phagophore. To date, the origin of the phagophore membrane remains controversial, as various organelles have been speculated to be the responsible membrane donors. However, various links have implicated mitochondria and mitochondrial-derived PE in the formation and expansion of at least some autophagosomes.

Over 30 proteins are involved in the various forms of autophagy in yeast, most of which are conserved in mammals (Reggiori and Klionsky, 2013). One of these components, Atg8p, and its functional mammalian ortholog LC3 (microtubule-associated protein light chain 3; Tanida et al., 2001), is covalently attached to the headgroup of PE, anchoring it to the developing autophagosomal membrane (Kabeya et al., 2000; Kirisako et al., 1999). Lipidation of Atg8p affects membrane dynamics during different stages of autophagosome formation since the association and disassociation of Atg8p/ LC3 with autophagosomal 
membranes plays an important role in determining the ultimate size of the autophagosome formed (Nair et al., 2012; Xie et al., 2008).

The process by which Atg8p is modified by PE occurs in an ubiquitin-like fashion where Atg8p is transferred and activated between cysteine residues on Atg proteins prior to being anchored to the phagophore membrane (Figure 3; Mizushima et al., 2011; Reggiori and Klionsky, 2013). Atg8p is synthesized in the cytosol where Atg4p, a cysteine protease, cleaves the C-terminal arginine of Atg8p exposing an essential N-terminal glycine residue (Kirisako et al., 2000). Atg7p recognizes the exposed glycine residue and binds Atg8p in an ATP-dependent manner prior to transferring it Atg3p (Ichimura et al., 2000). In mouse embryonic stem cells, membrane association of LC3 is dependent upon formation of the ATG12-ATG5 autophagy conjugation system (Mizushima et al., 2001). Indeed, further studies in yeast (Hanada et al., 2007; Sakoh-Nakatogawa et al., 2013) and structural characterization of the yeast and mammalian ATG12-ATG5 conjugate (Noda et al., 2013; Otomo et al., 2013) verified the activity of this complex in functioning as a platform that directly interacts with ATG3 and enhances/ specifies attachment of the N-terminal glycine residue of Atg8p/LC3 to the primary amine group of PE. Although the process of autophagosome formation involves the coordinated activity of various ATG proteins, the importance of conjugating PE to Atg8p is evidenced by the fact that autophagic activity decreases when the C-terminal glycine of Atg8p is removed (Hemelaar et al., 2003; Kim et al., 2001; Kirisako et al., 2000; Noda et al., 1995). In its final modification step, Atg8p is cleaved from the autophagosomal membrane at its C-terminal glycine residue by Atg $4 p$ (the second time Atg8p is cleaved by Atg4p), an event that controls the size of the autophagosome (Nair et al., 2012; Xie et al., 2008).

Under nutrient starving conditions, the mitochondrial outer membrane supplies lipids for autophagosome biogenesis in a manner that is independent of mitophagy (Hailey et al., 2010), a form of macroautophagy that removes damaged or excess mitochondria (Twig and Shirihai, 2010). This process is dependent on ER-mitochondria contact sites as deletion of $M F N 2$, which encodes a previously mentioned protein involved in mitochondrial fusion and ER-mitochondria tethering (de Brito and Scorrano, 2008), ablates induction of autophagy in normal rat kidney cells (Hailey et al., 2010). Interestingly, upon its addition to cells, the fluorescent lipid probe, NBD-PS, is initially present in the ER and accumulates in mitochondria over time, which is consistent with its subsequent conversion to NBD-PE by PSD1. Upon serum starvation, the mitochondrial NBD signal shifts to autophagosomes suggesting that mitochondrial-derived $\mathrm{PE}$ is used for autophagosome membrane formation (Hailey et al., 2010). However, whether the NBD signal detected in autophagosomes upon starvation was in fact NBD-PE was not experimentally verified. The origin of phagophore membranes is debated in the autophagy field (Mizushima et al., 2011; Tooze and Yoshimori, 2010) although electron microscope 3D tomography and cofractionation studies support a role for the MAM as also contributing to this process (Hamasaki et al., 2013).

A recent study has shown that PE-lipidation of Atg8p competes for the same pool of PE that is required for GPI anchor formation and PC synthesis. Growth of a yeast strain harboring a temperature sensitive (ts) allele of Mcd4p (Gaynor et al., 1999), a protein that appends a phosphoethanolamine group to the GPI anchor glycan core (Hong et al., 1999), is rescued at 
the nonpermissive temperature when genes encoding the PE-methylation enzyme, Pem1p, or either Atg7p or Atg14p, are deleted (Wilson-Zbinden et al., 2015). A decrease in Mcd4p activity results in accumulation of GPI-anchored proteins in the ER. By disrupting

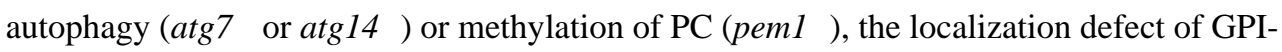
anchored proteins is restored. Overexpression of Pem1p is lethal to the $m c d 4$-ts yeast strain presumably by increasing the conversion of $\mathrm{PE}$ to $\mathrm{PC}$, thus reducing the pool of PE available for GPI anchor formation. Consistent with this idea, reducing cellular PE levels by deleting PSD2 or disrupting the CDP-ethanolamine pathway also impairs growth of the mcd4-ts yeast strain (Wilson-Zbinden et al., 2015). The availability of PE as a substrate for these processes is a potentially limiting factor that may regulate flux through each pathway.

High PE levels also positively regulate longevity in yeast and mammalian cells (Rockenfeller et al., 2015). This effect correlates with induction of autophagy as measured by levels of Atg8p and LC3 lipidation in cells supplemented with ethanolamine.

Additionally, fly lifespan is extended upon ethanolamine supplementation although the role of autophagy in these latter findings remains to be validated. Nonetheless, these studies illustrate the interplay between PE metabolism and processes that require PE as a substrate, suggesting that further research may reveal the coregulation of these functions.

\section{PE and Diseases}

PE influences a variety of cellular processes and the stability and function of numerous membrane proteins. Mice lacking either of the two major PE-producing pathways are inviable (Fullerton et al., 2009; Steenbergen et al., 2005). Consequently, impairments in the major PE biosynthetic pathways are incompatible with life and thus significant defects in the metabolism of PE are presumably eliminated during mammalian development. However, slight impairments that result in a change in PE abundance are associated with Alzheimer's and Parkinson's disease. A critical PC:PE ratio in the liver is also implicated in glucose metabolism (van der Veen et al., 2014) and liver disease (Li et al., 2006). Finally, PE is an important cofactor and membrane component that is required for the pathogenicity of a variety of infectious organisms (Chen et al., 2010; Deleault et al., 2012). In the following sections, we will highlight the emerging roles of PE in mammalian disease.

\subsection{Alzheimer's Disease}

Alzheimer's disease (AD) is a late onset neurodegenerative disorder characterized by abundant intracellular neurofibrillary tangles rich in hyperphosphorylated microtubuleassociated TAU and extracellular plaques of amyloid- $\beta(\mathrm{A} \beta)$ peptide derived from the amyloid precursor protein (APP; Goedert and Spillantini, 2006; Pimplikar, 2009; Selkoe, 2001). Pathophysiologically, AD is characterized by progressive neuronal loss, especially in the cortex and the hippocampus, which results in a decline in memory and cognition (Goedert and Spillantini, 2006). A $\beta$ peptides are derived from the sequential proteolytic cleavage of APP by $\beta$ - and $\gamma$-secretase (Haass and Selkoe, 2007). APP is a type I integral membrane protein with extracellular domains that are released upon cleavage by $a-$ or $\beta$ secretases, which cut APP at different positions (Figure 4(A); Buxbaum et al., 1998; Vassar et al., 1999). Both processes occur normally, precede cleavage by $\gamma$-secretase, and have beneficial physiological roles (Mattson et al., 1993; Ring et al., 2007). $\beta$-secretase cleavage 
of APP leaves a 99 amino acid C-terminal portion (C99) in the membrane (Selkoe, 2001; Vassar et al., 1999). $\gamma$-secretase cleaves within the TM domain of C99 (Edbauer et al., 2003; Qi-Takahara et al., 2005). This results in the liberation of the APP intracellular domain, which may have functions within the cell, and the release of $A \beta$. As a- secretase cleaves at a position more proximal to the transmembrane domain of APP than $\beta$-secretase, its activity prevents generation of $A \beta$ (Lammich et al., 1999) There are two factors that influence the propensity of $A \beta$ to form extracellular plaques: its abundance and its self-aggregation potential (Haass and Selkoe, 2007). The aggregation potential of $A \beta$ is dictated by the position within the TM domain of C99 that is cleaved by $\gamma$-secretase (Jung et al., 2014; Munter et al., 2007). Further, certain AD-associated mutations in APP enhance A $\beta$ aggregation without increasing its rate of production (Hutton et al., 1998; Mullan et al., 1992).

There are two types of $\mathrm{AD}$, namely, sporadic $\mathrm{AD}$, which constitute the majority of $\mathrm{AD}$ cases, and familial $\mathrm{AD}$, which is an early onset form of $\mathrm{AD}$ that has been genetically linked to various mutations. The familial form is caused by mutations in genes encoding APP or the presenilins (PS; Tanzi and Bertram, 2005). In humans, there are two homologs of PS, PS1 and PS2. PS (either PS1 or PS2) is a required component of the catalytic core of the $\gamma$ secretase complex and is thus essential for its activity (Wolfe et al., 1999). The actual course of the sporadic form of AD is not clearly understood. Nevertheless, the two forms of AD are both characterized by hyperphosphorylation of intracellular TAU and an increase in the abundance of $\mathrm{A} \beta$ peptides.

There has been substantial debate concerning the subcellular localization of the $\gamma$-secretase complex and where pathogenic APP cleavage in fact occurs (Ankarcrona and Hultenby, 2002; Annaert and De Strooper, 1999; Kimura et al., 2001; Marambaud et al., 2002; Pasternak et al., 2003; Vetrivel et al., 2004). However, PS1, PS2, and $\gamma$-secretase activity, as well as APP have been recently shown to localize to the MAM whose membranes are characterized as being detergent resistant (Area-Gomez et al., 2009; Browman et al., 2006; Poston et al., 2011). AD-associated mutations in PS1 or PS2 result in a closer apposition of the MAM with mitochondria, which correlates with an increase in PE synthesis and $\gamma$ secretase activity (Area-Gomez et al., 2009, 2012). This tighter association between the MAM and mitochondria increases the activity of resident enzymes in both compartments, including PSD1 (Area-Gomez et al., 2012). Overall, mutations in PS1 and PS2 lead to an increase in PE levels in mitochondria, MAM, and the plasma membrane (Area-Gomez et al., 2012). Subsequently, the rise in PE levels increases $\gamma$-secretase activity and generation of $A \beta$ (Figure 4(B)).

When PE levels are decreased, $\gamma$-secretase activity is reduced in mammalian cells and flies, and at least in the former model, a-secretase activity is increased (Figure 4(C); Nesic et al., 2012). Importantly, less $A \beta$ accumulates in PE-depleted mammalian cells and flies. Clearly, an alteration in lipid metabolism correlates with AD. Whether the changes in lipid composition affect the accessibility of the $\gamma$-secretase cleavage site of $A \beta$ is not known. Potentially, an increase in PE in the membrane obscures the $\alpha$-secretase cleavage site thus shifting the balance in favor of the sequential action of $\beta$ - and $\gamma$-secretases. Alternatively, perhaps the topology of one of the secretases ( $\beta$ or $\gamma$ ) is affected by PE, since PE has also 
been shown to influence certain membrane proteins in this manner (Section 4.1; Dowhan and Bogdanov, 2009). In summary, mutations in PS1 and PS2 increase MAM-mitochondria apposition although the underlying mechanism is not known (Area-Gomez et al., 2009, 2012). The tighter association between MAM and mitochondria increases production of PE and the amount of PE in membranes, which augments production of $A \beta$. How changes in the abundance of PE in membranes modulates the activity of $\alpha$ - and $\gamma$-secretase, is currently not known.

\subsection{Parkinson's Disease}

Parkinson's disease (PD) is morphologically characterized by the presence of intracellular proteinaceous inclusions called Lewy Bodies, which are mainly composed of cytosolic aggregates of a-synuclein in the affected neurons (Klein and Westenberger, 2012;

Spillantini et al., 1997). Accumulation of these aggregates results in the progressive loss of dopaminergic neurons in the midbrain region called the substantia nigra pars compacta (Dawson and Dawson, 2003; Polymeropoulos et al., 1997). The majority ( 90\%) of PD cases are sporadic; only $\sim 10 \%$ of PD cases have a familial history.

Even though over 28 chromosomal regions have either been directly or loosely associated with PD, to date there are only six genes that have been conclusively linked to PD (e.g., a mutation is sufficient to cause disease). Mutations in SNCA (PARK4) and LRRK2 (PARK8) result in autosomal dominant PD (Polymeropoulos et al., 1996, 1997; Singleton et al., 2003), while Parkin (PARK2), PINK1 (PARK6), DJ-1 (PARK7), and ATP13A2 (PARK9) mutations are linked with autosomal recessive PD (Abbas et al., 1999; Bonifati et al., 2003; Kitada et al., 1998). Here, we will only focus on mutations in the a-synuclein encoding gene, SNCA, which are associated with alterations in cellular PE levels. Patients with mutations in SNCA have early onset PD (age <50 years; Polymeropoulos et al., 1996). Currently there are five different missense mutations in a-synuclein as well as $S N C A$ duplications and triplications that have been associated with PD (Kara et al., 2013; Klein and Schlossmacher, 2006; Kruger et al., 1998; Polymeropoulos et al., 1997; Singleton et al., 2003; Uchiyama et al., 2008; Zarranz et al., 2004).

The mechanism(s) by which a-synuclein confers selective death of dopaminergic neurons is currently unclear. $a$-synuclein is found in presynaptic neurons where it is thought to participate in neurotransmitter vesicle release by promoting assembly of soluble $N$ ethylmaleimide-sensitive factor attachment protein receptor (SNARE) complexes (Burré et al., 2010). Overexpression of a-synuclein increases the pool of docked but unfused secretory vesicles with the end result being a decrease in neurotransmitter release (Nemani et al., 2010). While the majority of a-synuclein is cytosolic, it also associates with membranes including lipid rafts (Fortin et al., 2004). In fact, when the ability to interact with lipid rafts is disturbed, either through pharmacologic inhibition of lipid raft formation or introduction of a PD-associated mutation A30P, a-synuclein (mutant or wild-type) does not properly localize to synapses (Fortin et al., 2004). Interestingly, the MAM subcompartment of the ER has properties that are reminiscent of lipid rafts (Hayashi and Fujimoto, 2010) and a fraction of a-synuclein, but not the A30P mutant unable to bind lipid rafts, cofractionates with this compartment (Figure 5(A); Guardia-Laguarta et al., 2014). When the association of a- 
synuclein and MAM is disturbed or diminished, mitochondria-ER contacts are reduced, mitochondria become fragmented, PS synthesis in MAM and conversion to PE in mitochondria is reduced, and mitochondrial $\mathrm{Ca}^{2+}$ buffering following release of $\mathrm{ER}-\mathrm{Ca}^{2+}$ stores is impaired (Figure 5(B); Cali et al., 2012; Guardia-Laguarta et al., 2014). These results indicate that in addition to its synaptic function, a-synuclein serves an important role at the ER-mitochondrial interface (Figure 5(A)). Relevant to PD associated with duplications and triplications of SNCA, the severe overexpression of a-synuclein increases mitochondrial fragmentation (Guardia-Laguarta et al., 2014) and reduces mitochondrial $\mathrm{Ca}^{2+}$ accumulation (Cali et al., 2012). Whether these overexpression-based alterations result from too much, or instead not enough (e.g., at high levels of expression, cytosolic asynuclein aggregation is stimulated), MAM-associated a-synuclein is presently unclear.

In $p s d 1 \Delta$ yeast, heterologously expressed a-synuclein accumulates in the ER at the expense of its normal association with the plasma membrane; this altered subcellular distribution correlates with an increase in ER stress and yeast doubling time (Figure 5(C); Wang et al., 2014). While not improving the mitochondrial dysfunctions caused by the absence of Psd1p function, ethanolamine supplementation, which drives production of PE via the CDPethanolamine pathway, restores the normal a-synuclein plasma membrane localization in psdl $1 \Delta$ yeast and rescues the phenotypes that correlate with its accumulation at the ER. Similarly, in a worm PD model, the survival of dopaminergic neurons expressing asynuclein is reduced in the absence of Psd1p. The addition of ethanolamine prevents this neurodegeneration in a manner that is dependent on a functional CDP-ethanolamine pathway for PE production (Wang et al., 2014). Thus, when PE is limiting, a-synuclein homeostasis is perturbed such that it is more toxic to its cellular host.

How does limiting amounts of PE disturb a-synuclein homeostasis? An intriguing possibility is centered on PE's role as a required substrate for GPI anchor formation (Menon and Stevens, 1992). The biogenesis of GPI-anchored proteins, which associate with lipid rafts, is impaired in $p s d 1 \Delta$ yeast (Birner et al., 2001; Wang et al., 2014). a-synuclein also accumulates intracellularly in a yeast GPI anchor biosynthesis mutant (Wang et al., 2014). Interestingly, the ability of an enzyme, which is recruited to lipid rafts by GPI-anchored proteins (Okamoto et al., 2006) to access the plasma membrane is reduced in $p s d 1 \Delta$ yeast similar to a-synuclein (Wang et al., 2014). As GPI-anchored proteins and a-synuclein, which lacks a TM domain and can bind lipids directly (Chandra et al., 2003), occupy opposite sides of the membrane, it is unlikely that a-synuclein is recruited to lipid rafts by GPI-anchored proteins. Therefore, it is tempting to speculate that in the absence of robust GPI anchor formation (e.g., in $p s d 1 \Delta$ yeast), there is a defect in the ability to form lipid rafts that are recognized by a-synuclein, or alternatively, the ability of lipid rafts to traffic out of the ER is reduced. Regardless of the exact mechanism, the end result is a disturbance in asynuclein homeostasis that increases its cellular toxicity.

\subsection{The Balance of PE and PC in Liver Steatosis and Steatohepatitis}

With over $30 \%$ of adults affected in developed countries, nonalcoholic fatty liver disease (NAFLD) is the most prevalent form of liver disease in the world (Dietrich and Hellerbrand, 2014). NAFLD encompasses a range of liver maladies that are diagnosed by assessing the 
level of fat deposits in and injury to hepatocytes (Tuyama and Chang, 2012). Steatosis or fatty liver, develops when excess lipids are stored as triglycerides in fat droplets or instead incorporated and secreted by the liver as very low-density lipoproteins. Increased accumulation of fat in liver cells subsequently leads to disrupted cellular functions with desensitized responses to metabolic changes making cells more susceptible to lipotoxicity and ER and oxidative stress.

Nonalcoholic steatohepatitis (NASH) involves liver steatosis, inflammation, and hepatocyte injury (Tuyama and Chang, 2012). Hepatocytes show features of "ballooning" when membrane integrity becomes compromised, which can lead to cell rupture and induction of an inflammatory response (Kleiner et al., 2005). Subsequent tissue injury leads to fibrosis in the liver, which can later mature into liver cirrhosis or cancer.

Risk factors for NAFLD include age (Frith et al., 2009), ethnicity, but most notably life style as NAFLD is often associated with obesity (Williams et al., 2011), insulin resistance (Gastaldelli et al., 2009), heart disease (Gastaldelli et al., 2009; Mirbagheri et al., 2007), and metabolic syndrome (combination of obesity, hypertension, hypertriglyceridemia, low levels of high-density lipoprotein, and/or hyperglycemia; Ryan et al., 2005; Tuyama and Chang, 2012; Williams et al., 2011). Alarmingly, it is speculated that the majority of NAFLD cases go undiagnosed, as invasive liver biopsies are the most reliable form of assessing liver damage (although some predictive tests and biomarkers for NASH exist, they may not be entirely accurate; Dietrich and Hellerbrand, 2014; Tuyama and Chang, 2012). Further, as no pharmacological treatments for NAFLD exist, patients are presently prescribed regimented diets and exercise plans designed to prevent further tissue damage and diminish the severity of steatosis.

Mice with a hepatocyte-specific deletion of PCYT2, encoding CTP: phosphoethanolamine cytidylyltransferase in the CDP-ethanolamine pathway, have normal growth and differentiation of liver cells even though there is a 50\% drop in cellular PE levels (Leonardi et al., 2009). The remaining PE is made by the mitochondrial Psd pathway and is sufficient to support basic cellular function. However, mice lacking PCYT2 in hepatocytes develop steatosis that stems from a 10-fold increase in hepatocyte triglyceride synthesis. Thus, the DAG that is normally consumed to produce PE by the CDP-ethanolamine pathway is instead converted to triglycerides, which promote lipid droplet formation (Fullerton et al., 2009; Leonardi et al., 2009).

Hepatocytes generate $30 \%$ of their total PC from the trimethylation of PE by PEMT (Sundler and Akesson, 1975b). pemt ${ }^{-1-}$ mice develop steatohepatitis and progress to liver failure within 3 days of being fed a choline-deficient diet (choline supplementation supports production of PC through the CDP-choline pathway; Walkey et al., 1998). The high demand for hepatic PC secretion into bile reduces levels of PC by $50 \%$ in pemt ${ }^{-1-}$ mice (Li et al., 2006; Walkey et al., 1998). Secretion of PC into bile is mediated by MDR2 (multiple drugresistant protein 2), a PC-specific flippase (Ruetz and Gros, 1994; Smit et al., 1993). Surprisingly, $m d r 2^{-/-}$x pemt $^{-/-}$mice fed with a choline-deficient diet are resistant to the development of steatohepatitis and liver failure despite the fact that PC levels are still decreased by $50 \%$ (Li et al., 2005, 2006). The varied sensitivity of $p e m t^{-/-}$and $m d r 2^{-/-} \times$ 
$p e m t^{-/-}$mice to choline deprivation is due to a striking difference in their respective plasma membrane PC:PE ratios (Li et al., 2006). Interestingly, in $m d r 2^{-/-} \times p e m t^{-/-}$mice in which the ability to secrete PC into the bile is impaired, $\mathrm{PE}$ and PC catabolism is increased to maintain the PC:PE ratio. The decrease in the PC:PE ratio in pemt ${ }^{-/}$mice increases membrane permeability and facilitates hepatocyte damage. Depletion of CTP:phosphoethanolamine cytidylyltransferase in $p e m t^{-/-}$mice increases the PC:PE ratio, restores membrane integrity, and prevents the development of steatohepatitis although intriguingly, lipid droplets still accumulate in liver tissues (Li et al., 2006). Collectively, these results indicate that the plasma membrane PC:PE ratio is critical for hepatocyte cell integrity and that PC produced by the trimethylation of PE is physiologically important in maintaining this lipid balance.

Importantly, a decrease in the PC:PE ratio was also observed in liver biopsies from patients with nonalcoholic steatohepatitis (Arendt et al., 2013; Li et al., 2006). Thus, the maintenance of the PC:PE ratio in hepatocyte membranes is critical for the integrity of the cell although each individual phospholipid plays a different role in hepatic lipid metabolism. As PC is essential for bile secretion and incorporation into lipoproteins, PC synthesis is of particular importance for liver physiology. An increase in the ratio of hepatic PE to PC makes membranes more permeable and can account for tissue damage in pemt ${ }^{-1-}$ mice (Figure 6(A) and (B); Li et al., 2006). In contrast, depletion of the CDP-ethanolamine pathway in hepatocytes leads to liver steatosis due to increased triglyceride synthesis (Figure 6(C) and (D); Leonardi et al., 2009). Therefore, changes that alter the relative abundance of PE or that directly impair PE metabolism can disturb liver function by multiple mechanisms.

\subsection{Infectious Disease}

5.4.1 Pathogenic Prion Generation-Prions are infectious proteins that contain a pathogenic conformer of the mammalian prion protein $\left(\operatorname{PrP}^{\mathrm{sc}}\right)$, which can be produced by the noninfective mammalian conformer $\left(\operatorname{PrP}^{\mathrm{c}}\right)$, RNA, and lipid molecules (Deleault et al., 2003, 2012). Prion infectivity and strain properties are encoded by specific protein conformations (Kretzschmar and Tatzelt, 2013). However, neither the tertiary structure of infectious $\mathrm{PrP}^{\mathrm{sc}}$ nor the molecular mechanism(s) responsible for generating this infectious form are known. Prp ${ }^{\mathrm{sc}}$ molecules exist as insoluble aggregates, which do not allow for the determination of their crystal structure. Prion propagation occurs independent of the presence of nucleic acid (Deleault et al., 2012). NMR and mass spectrometry identified PE as a cofactor that associates with recombinant PrP. Moreover, the association of PE transforms recombinant PrP into a form capable of infecting mice. Astonishingly, treatment with phospholipase $\mathrm{C}$, which removes the headgroups from phospholipids including $\mathrm{PE}$, ablates the ability of $\mathrm{PrP}^{\mathrm{sc}}$ to infect brain tissues (Deleault et al., 2012). This suggests that the $\mathrm{PE}$ is a required cofactor necessary for the propagation of at least some infective prions.

5.4.2 Candida Virulence-Candidiasis (or candidemia) infection is the leading cause of opportunistic fungal infections in immunocompromised individuals where it has a $33.9 \%$ mortality rate (Pfaller and Diekema, 2007). Additionally, candida infections are becoming increasingly resistant to existing therapeutic treatments (Lortholary et al., 2014). Thus, studies to find ways to specifically target these infections are of critical biomedical 
importance (Thomas et al., 2013). Cell wall stability is essential for the virulence of Candida albicans (Ruiz-Herrera et al., 2006). Depletion of PE by targeting PSD1, PSD2, or PSS1 in C. albicans reduces its infectivity in an immunocompromised mouse model (Chen et al., 2010). Growth of $p s s 1 \Delta$ and $p s d 1 \Delta p s d 2 \Delta$ strains of $C$. albicans is decreased on dextrosebased agar plates in the absence of osmotic stabilizers (sorbitol, $\mathrm{CaCl}_{2}$, or $\mathrm{NaCl}$ ). In addition, $p s s 1 \Delta$ and $p s d 1 \Delta p s d 2 \Delta$ strains are more sensitive to caspofungin treatment suggesting that cell wall integrity is affected in the absence of these lipid-synthesizing proteins. This is complemented by studies in $p s d 1 \Delta$ yeast where the lower levels of PE impair GPI-anchor formation, which compromises cell wall integrity (Wang et al., 2014). Thus, inhibiting the Psd pathway in a manner that specifically targets proteins conserved in fungi but not humans (e.g., PSS1) represents a candidate therapeutic approach to combat fungal infections.

\section{Concluding Remarks}

$\mathrm{PE}$ is an abundant membrane phospholipid that is essential for membrane integrity, cell division, maximum mitochondrial respiratory function, membrane protein topology, and function, an important precursor for PC, and can be used to modify certain proteins. These modifications can be necessary for proper localization and/or function. One such example includes GPI-anchored proteins, which are retained in the ER when PE is limiting. Traditionally, the main function attributed to PE other than as a precursor to $\mathrm{PC}$, has been associated with its nonbilayer forming structural capacity that is implicated in membrane fusion and fission events, cytokinesis, and vacuolar delivery. However, as illustrated in the present review, the functions attributed to PE go well beyond tradition.

Eukaryotes have multiple PE biosynthetic pathways. The existence of a multitude of pathways reflects the importance of PE in a cell. However, that both major pathways of PE synthesis, the CDP-ethanolamine pathway and the phosphatidylserine decarboxylation pathway, are required during mammalian development indicates that not all PE is made the same. A systematic assessment of the relative importance of each PE-producing pathway in different cells and tissues has not been provided. Such information is expected to identify functions and processes that are uniquely dependent on a given pathway.

While most studies have focused on the roles of different proteins in the development of pathologies, less has been done from a lipid perspective. Recent advances in research highlight the need to incorporate the study of lipids, as they are critical determinants of protein structure and function. The link between PE metabolism and disease is emerging and here we have highlighted those disease states in which PE is associated. Interestingly, PE can contribute to disease pathogenesis by being either increased or decreased (Alzheimer's and Parkinson's diseases). Our understanding of the role of PE in AD, PD, liver disease, fungal pathogenicity, and prion infectivity is just in its nascent stage. As such, defining the mechanistic role of PE in these and likely additional human diseases will be a main research objective in the coming years.

\section{Acknowledgments}

The authors' work was supported by National Institutes of Health Grant R01GM111548 (S.M.C.). 


\section{References}

Abbas N, Lucking CB, Ricard S, Durr A, Bonifati V, De Michele G, Bouley S, Vaughan JR, Gasser T, Marconi R, Broussolle E, Brefel-Courbon C, Harhangi BS, Oostra BA, Fabrizio E, Bohme GA, Pradier L, Wood NW, Filla A, Meco G, Denefle P, Agid Y, Brice A. A wide variety of mutations in the parkin gene are responsible for autosomal recessive parkinsonism in Europe. French Parkinson's Disease Genetics Study Group and the European Consortium on Genetic Susceptibility in Parkinson's Disease. Hum Mol Genet. 1999; 8:567-574. [PubMed: 10072423]

Achleitner G, Gaigg B, Krasser A, Kainersdorfer E, Kohlwein SD, Perktold A, Zellnig G, Daum G. Association between the endoplasmic reticulum and mitochondria of yeast facilitates interorganelle transport of phospholipids through membrane contact. Eur J Biochem. 1999; 264:545-553. [PubMed: 10491102]

Achleitner G, Zweytick D, Trotter PJ, Voelker DR, Daum G. Synthesis and intracellular transport of aminoglycerophospholipids in permeabilized cells of the yeast, Saccharomycescerevisiae. J Biol Chem. 1995; 270:29836-29842. [PubMed: 8530379]

Acín-Pérez R, Fernández-Silva P, Peleato ML, Pérez-Martos A, Enriquez JA. Respiratory active mitochondrial supercomplexes. Mol Cell. 2008; 32:529-539. [PubMed: 19026783]

Alexander C, Votruba M, Pesch UE, Thiselton DL, Mayer S, Moore A, Rodriguez M, Kellner U, LeoKottler B, Auburger G, Bhattacharya SS, Wissinger B. OPA1, encoding a dynamin-related GTPase, is mutated in autosomal dominant optic atrophy linked to chromosome 3q28. Nat Genet. 2000; 26:211-215. [PubMed: 11017080]

Alkhaja AK, Jans DC, Nikolov M, Vukotic M, Lytovchenko O, Ludewig F, Schliebs W, Riedel D, Urlaub H, Jakobs S, Deckers M. MINOS1 is a conserved component of mitofilin complexes and required for mitochondrial function and cristae organization. Mol Biol Cell. 2012; 23:247-257. [PubMed: 22114354]

Ankarcrona M, Hultenby K. Presenilin-1 is located in rat mitochondria. Biochem Biophys Res Commun. 2002; 295:766-770. [PubMed: 12099705]

Annaert W, De Strooper B. Presenilins: molecular switches between proteolysis and signal transduction. Trends Neurosci. 1999; 22:439-443. [PubMed: 10481190]

Area-Gomez E, de Groof AJ, Boldogh I, Bird TD, Gibson GE, Koehler CM, Yu WH, Duff KE, Yaffe MP, Pon LA, Schon EA. Presenilins are enriched in endoplasmic reticulum membranes associated with mitochondria. Am J Pathol. 2009; 175:1810-1816. [PubMed: 19834068]

Area-Gomez E, Del Carmen Lara Castillo M, Tambini MD, Guardia-Laguarta C, de Groof AJ, Madra M, Ikenouchi J, Umeda M, Bird TD, Sturley SL, Schon EA. Upregulated function of mitochondria-associated ER membranes in Alzheimer disease. EMBO J. 2012; 31:4106-4123. [PubMed: 22892566]

Arendt BM, Ma DW, Simons B, Noureldin SA, Therapondos G, Guindi M, Sherman M, Allard JP. Nonalcoholic fatty liver disease is associated with lower hepatic and erythrocyte ratios of phosphatidylcholine to phosphatidylethanolamine. Appl Physiol Nutr Metab. 2013; 38:334-340. [PubMed: 23537027]

Arikketh D, Nelson R, Vance JE. Defining the importance of phosphatidylserine synthase-1 (PSS1): unexpected viability of PSS1-deficient mice. J Biol Chem. 2008; 283:12888-12897. [PubMed: 18343815]

Atkinson KD, Jensen B, Kolat AI, Storm EM, Henry SA, Fogel S. Yeast mutants auxotrophic for choline or ethanolamine. J Bacteriol. 1980; 141:558-564. [PubMed: 6988386]

Bae-Lee MS, Carman GM. Phosphatidylserine synthesis in Saccharomycescerevisiae. Purification and characterization of membrane-associated phosphatidylserine synthase. J Biol Chem. 1984; 259:10857-10862. [PubMed: 6088519]

Baile MG, Lu YW, Claypool SM. The topology and regulation of cardiolipin biosynthesis and remodeling in yeast. Chem Phys Lipids. 2014; 179:25-31. [PubMed: 24184646]

Becker T, Horvath SE, Bottinger L, Gebert N, Daum G, Pfanner N. Role of phosphatidylethanolamine in the biogenesis of mitochondrial outer membrane proteins. J Biol Chem. 2013; 288:1645116459. [PubMed: 23625917] 
Berger KH, Sogo LF, Yaffe MP. Mdm12p, a component required for mitochondrial inheritance that is conserved between budding and fission yeast. J Cell Biol. 1997; 136:545-553. [PubMed: 9024686]

Bergo MO, Gavino BJ, Steenbergen R, Sturbois B, Parlow AF, Sanan DA, Skarnes WC, Vance JE, Young SG. Defining the importance of phosphatidylserine synthase 2 in mice. J Biol Chem. 2002; 277:47701-47708. [PubMed: 12361952]

Birner R, Burgermeister M, Schneiter R, Daum G. Roles of phosphatidylethanolamine and of its several biosynthetic pathways in Saccharomyces cerevisiae. Mol Biol Cell. 2001; 12:997-1007. [PubMed: 11294902]

Bjerve KS. Phospholipid substrate-specificity of the L-serine base-exchange enzyme in rat liver microsomal fraction. Biochem J. 1984; 219:781-784. [PubMed: 6430274]

Bleazard W, McCaffery JM, King EJ, Bale S, Mozdy A, Tieu Q, Nunnari J, Shaw JM. The dynaminrelated GTPase Dnm1 regulates mitochondrial fission in yeast. Nat Cell Biol. 1999; 1:298-304. [PubMed: 10559943]

Bleijerveld OB, Brouwers JF, Vaandrager AB, Helms JB, Houweling M. The CDP-ethanolamine pathway and phosphatidylserine decarboxylation generate different phosphatidylethanolamine molecular species. J Biol Chem. 2007; 282:28362-28372. [PubMed: 17673461]

Bogdanov M, Dowhan W. Phosphatidylethanolamine is required for invivo function of the membraneassociated lactose permease of Escherichia coli. J Biol Chem. 1995; 270:732-739. [PubMed: 7822303]

Bogdanov M, Dowhan W. Phospholipid-assisted protein folding: phosphatidylethanolamine is required at a late step of the conformational maturation of the polytopic membrane protein lactose permease. EMBO J. 1998; 17:5255-5264. [PubMed: 9736605]

Bogdanov M, Dowhan W. Lipid-assisted protein folding. J Biol Chem. 1999; 274:36827-36830. [PubMed: 10601231]

Bogdanov M, Dowhan W, Vitrac H. Lipids and topological rules governing membrane protein assembly. Biochim Biophys Acta. 2014; 1843:1475-1488. [PubMed: 24341994]

Bogdanov M, Heacock PN, Dowhan W. A polytopic membrane protein displays a reversible topology dependent on membrane lipid composition. EMBO J. 2002; 21:2107-2116. [PubMed: 11980707]

Bogdanov M, Xie J, Dowhan W. Lipid-protein interactions drive membrane protein topogenesis in accordance with the positive inside rule. J Biol Chem. 2009; 284:9637-9641. [PubMed: 19074771]

Bogdanov M, Xie J, Heacock P, Dowhan W. To flip or not to flip: lipid-protein charge interactions are a determinant of final membrane protein topology. J Cell Biol. 2008; 182:925-935. [PubMed: 18779371]

Bonifati V, Rizzu P, van Baren MJ, Schaap O, Breedveld GJ, Krieger E, Dekker MC, Squitieri F, Ibanez P, Joosse M, van Dongen JW, Vanacore N, van Swieten JC, Brice A, Meco G, van Duijn CM, Oostra BA, Heutink P. Mutations in the DJ-1 gene associated with autosomal recessive earlyonset parkinsonism. Science. 2003; 299:256-259. [PubMed: 12446870]

Borkenhagen LF, Kennedy EP, Fielding L. Enzymatic formation and decarboxylation of phosphatidylserine. J Biol Chem. 1961; 236:PC28-PC30.

Bottinger L, Horvath SE, Kleinschroth T, Hunte C, Daum G, Pfanner N, Becker T. Phosphatidylethanolamine and cardiolipin differentially affect the stability of mitochondrial respiratory chain supercomplexes. J Mol Biol. 2012; 423:677-686. [PubMed: 22971339]

Bremer J, Greenberg DM. Methyl transfering enzyme system of microsomes in the biosynthesis of lecithin (phosphatidylcholine). Biochim Biophys Acta. 1961; 46:205-216.

Bretscher MS. Asymmetrical lipid bilayer structure for biological membranes. Nat New Biol. 1972; 236:11-12. [PubMed: 4502419]

Browman DT, Resek ME, Zajchowski LD, Robbins SM. Erlin-1 and erlin-2 are novel members of the prohibitin family of proteins that define lipid-raft-like domains of the ER. J Cell Sci. 2006; 119:3149-3160. [PubMed: 16835267]

Burgermeister M, Birner-Grunberger R, Nebauer R, Daum G. Contribution of different pathways to the supply of phosphatidylethanolamine and phosphatidylcholine to mitochondrial membranes of 
the yeast Saccharomyces cerevisiae. Biochim Biophys Acta. 2004; 1686:161-168. [PubMed: 15522832]

Burgess SM, Delannoy M, Jensen RE. MMM1 encodes a mitochondrial outer membrane protein essential for establishing and maintaining the structure of yeast mitochondria. J Cell Biol. 1994; 126:1375-1391. [PubMed: 8089172]

Burré J, Sharma M, Tsetsenis T, Buchman V, Etherton MR, Südhof TC. a-Synuclein promotes SNARE-complex assembly in vivo and in vitro. Science. 2010; 329:1663-1667. [PubMed: 20798282]

Buxbaum JD, Liu KN, Luo Y, Slack JL, Stocking KL, Peschon JJ, Johnson RS, Castner BJ, Cerretti DP, Black RA. Evidence that tumor necrosis factor alpha converting enzyme is involved in regulated alpha-secretase cleavage of the Alzheimer amyloid protein precursor. J Biol Chem. 1998; 273:27765-27767. [PubMed: 9774383]

Cali T, Ottolini D, Negro A, Brini M. Alpha-synuclein controls mitochondrial calcium homeostasis by enhancing endoplasmic reticulum-mitochondria interactions. J Biol Chem. 2012; 287:1791417929. [PubMed: 22453917]

Chacinska A, Koehler CM, Milenkovic D, Lithgow T, Pfanner N. Importing mitochondrial proteins: machineries and mechanisms. Cell. 2009; 138:628-644. [PubMed: 19703392]

Chan EY, McQuibban GA. Phosphatidylserine decarboxylase 1 (Psd1) promotes mitochondrial fusion by regulating the biophysical properties of the mitochondrial membrane and alternative topogenesis of mitochondrial genome maintenance protein 1 (Mgm1). J Biol Chem. 2012; 287:40131-40139. [PubMed: 23045528]

Chandra S, Chen X, Rizo J, Jahn R, Südhof TC. A broken a-helix in folded a-synuclein. J Biol Chem. 2003; 278:15313-15318. [PubMed: 12586824]

Chang SC, Heacock PN, Mileykovskaya E, Voelker DR, Dowhan W. Isolation and characterization of the gene (CLS1) encoding cardiolipin synthase in Saccharomyces cerevisiae. J Biol Chem. 1998; 273:14933-14941. [PubMed: 9614098]

Chen D, Zhang XY, Shi Y. Identification and functional characterization of hCLS1, a human cardiolipin synthase localized in mitochondria. Biochem J. 2006; 398:169-176. [PubMed: 16716149]

Chen H, Detmer SA, Ewald AJ, Griffin EE, Fraser SE, Chan DC. Mitofusins Mfn1 and Mfn2 coordinately regulate mitochondrial fusion and are essential for embryonic development. J Cell Biol. 2003; 160:189-200. [PubMed: 12527753]

Chen YL, Montedonico AE, Kauffman S, Dunlap JR, Menn FM, Reynolds TB. Phosphatidylserine synthase and phosphatidylserine decarboxylase are essential for cell wall integrity and virulence in Candida albicans. Mol Microbiol. 2010; 75:1112-1132. [PubMed: 20132453]

Choi JY, Augagneur Y, Ben Mamoun C, Voelker DR. Identification of gene encoding Plasmodium knowlesi phosphatidylserine decarboxylase by genetic complementation in yeast and characterization of in vitro maturation of encoded enzyme. J Biol Chem. 2012; 287:222-232. [PubMed: 22057268]

Choi JY, Duraisingh MT, Marti M, Ben Mamoun C, Voelker DR. From protease to decarboxylase: The molecular metamorphosis of phosphatidylserine decarboxylase. J Biol Chem. 2015; 290:10972-10980. [PubMed: 25724650]

Clancey CJ, Chang SC, Dowhan W. Cloning of a gene (PSD1) encoding phosphatidylserine decarboxylase from Saccharomyces cerevisiae by complementation of an Escherichiacoli mutant. J Biol Chem. 1993; 268:24580-24590. [PubMed: 8227017]

Claypool SM, Koehler CM. The complexity of cardiolipin in health and disease. Trends Biochem Sci. 2012; 37:32-41. [PubMed: 22014644]

Colbeau A, Nachbaur J, Vignais PM. Enzymic characterization and lipid composition of rat liver subcellular membranes. Biochim Biophys Acta. 1971; 249:462-492. [PubMed: 5134192]

Connerth M, Tatsuta T, Haag M, Klecker T, Westermann B, Langer T. Intramitochondrial transport of phosphatidic acid in yeast by a lipid transfer protein. Science. 2012; 338:815-818. [PubMed: 23042293]

Cowart LA, Obeid LM. Yeast sphingolipids: recent developments in understanding biosynthesis, regulation, and function. Biochim Biophys Acta. 2007; 1771:421-431. [PubMed: 16997623] 
Cruciat CM, Brunner S, Baumann F, Neupert W, Stuart RA. The cytochrome bc1 and cytochrome c oxidase complexes associate to form a single supracomplex in yeast mitochondria. J Biol Chem. 2000; 275:18093-18098. [PubMed: 10764779]

Csordas G, Renken C, Varnai P, Walter L, Weaver D, Buttle KF, Balla T, Mannella CA, Hajnoczky G. Structural and functional features and significance of the physical linkage between ER and mitochondria. J Cell Biol. 2006; 174:915-921. [PubMed: 16982799]

Cui Z, Vance JE, Chen MH, Voelker DR, Vance DE. Cloning and expression of a novel phosphatidylethanolamine N-methyltransferase. A specific biochemical and cytological marker for a unique membrane fraction in rat liver. J Biol Chem. 1993; 268:16655-16663. [PubMed: 8344945]

Daum G. Lipids of mitochondria. Biochim Biophys Acta. 1985; 822:1-42. [PubMed: 2408671]

Daum G, Heidorn E, Paltauf F. Intracellular transfer of phospholipids in the yeast Saccharomycescerevisiae. Biochim Biophys Acta. 1986; 878:93-101. [PubMed: 3524689]

Dawson TM, Dawson VL. Molecular pathways of neurodegeneration in Parkinson's disease. Science. 2003; 302:819-822. [PubMed: 14593166]

de Brito OM, Scorrano L. Mitofusin 2 tethers endoplasmic reticulum to mitochondria. Nature. 2008; 456:605-610. [PubMed: 19052620]

de Kroon AI, Koorengevel MC, Vromans TA, de Kruijff B. Continuous equilibration of phosphatidylcholine and its precursors between endoplasmic reticulum and mitochondria in yeast. Mol Biol Cell. 2003; 14:2142-2150. [PubMed: 12802081]

DeChavigny A, Heacock PN, Dowhan W. Sequence and inactivation of the pss gene of Escherichiacoli. Phosphatidylethanolamine may not be essential for cell viability. J Biol Chem. 1991; 266:10710. [PubMed: 2037609]

Deleault NR, Lucassen RW, Supattapone S. RNA molecules stimulate prion protein conversion. Nature. 2003; 425:717-720. [PubMed: 14562104]

Deleault NR, Piro JR, Walsh DJ, Wang F, Ma J, Geoghegan JC, Supattapone S. Isolation of phosphatidylethanolamine as a solitary cofactor for prion formation in the absence of nucleic acids. Proc Natl Acad Sci USA. 2012; 109:8546-8551. [PubMed: 22586108]

Delettre C, Lenaers G, Griffoin JM, Gigarel N, Lorenzo C, Belenguer P, Pelloquin L, Grosgeorge J, Turc-Carel C, Perret E, Astarie-Dequeker C, Lasquellec L, Arnaud B, Ducommun B, Kaplan J, Hamel CP. Nuclear gene OPA1, encoding a mitochondrial dynamin-related protein, is mutated in dominant optic atrophy. Nat Genet. 2000; 26:207-210. [PubMed: 11017079]

Dennis EA, Kennedy EP. Intracellular sites of lipid synthesis and the biogenesis of mitochondria. $\mathbf{J}$ Lipid Res. 1972; 13:263-267. [PubMed: 5016308]

Dietrich P, Hellerbrand C. Non-alcoholic fatty liver disease, obesity and the metabolic syndrome. Best Pract Res Clin Gastroenterol. 2014; 28:637-653. [PubMed: 25194181]

Dimmer KS, Fritz S, Fuchs F, Messerschmitt M, Weinbach N, Neupert W, Westermann B. Genetic basis of mitochondrial function and morphology in Saccharomycescerevisiae. Mol Biol Cell. 2002; 13:847-853. [PubMed: 11907266]

Dowhan W, Bogdanov M. Lipid-dependent membrane protein topogenesis. Annu Rev Biochem. 2009; 78:515-540. [PubMed: 19489728]

Dowhan W, Wickner WT, Kennedy EP. Purification and properties of phosphatidylserine decarboxylase from Escherichia coli. J Biol Chem. 1974; 249:3079-3084. [PubMed: 4598120]

Drin G. Topological regulation of lipid balance in cells. Annu Rev Biochem. 2014; 83:51-77. [PubMed: 24606148]

Edbauer D, Winkler E, Regula JT, Pesold B, Steiner H, Haass C. Reconstitution of gamma-secretase activity. Nat Cell Biol. 2003; 5:486-488. [PubMed: 12679784]

Elbaz-Alon Y, Rosenfeld-Gur E, Shinder V, Futerman AH, Geiger T, Schuldiner M. A dynamic interface between vacuoles and mitochondria in yeast. Dev Cell. 2014; 30:95-102. [PubMed: 25026036]

Emoto K, Kobayashi T, Yamaji A, Aizawa H, Yahara I, Inoue K, Umeda M. Redistribution of phosphatidylethanolamine at the cleavage furrow of dividing cells during cytokinesis. Proc Natl Acad Sci USA. 1996; 93:12867-12872. [PubMed: 8917511] 
Emoto K, Umeda M. An essential role for a membrane lipid in cytokinesis. Regulation of contractile ring disassembly by redistribution of phosphatidylethanolamine. J Cell Biol. 2000; 149:12151224. [PubMed: 10851019]

Espenshade PJ, Hughes AL. Regulation of sterol synthesis in eukaryotes. Annu Rev Genet. 2007; 41:401-427. [PubMed: 17666007]

Ferguson MA. The structure, biosynthesis and functions of glycosylphosphatidylinositol anchors, and the contributions of trypanosome research. J Cell Sci. 1999; 112(Pt 17):2799-2809. [PubMed: 10444375]

Flury I, Benachour A, Conzelmann A. YLL031c belongs to a novel family of membrane proteins involved in the transfer of ethanolaminephosphate onto the core structure of glycosylphosphatidylinositol anchors in yeast. J Biol Chem. 2000; 275:24458-24465. [PubMed: 10823837]

Fortin DL, Troyer MD, Nakamura K, Kubo S, Anthony MD, Edwards RH. Lipid rafts mediate the synaptic localization of alpha-synuclein. J Neurosci. 2004; 24:6715-6723. [PubMed: 15282274]

Friedman JR, Nunnari J. Mitochondrial form and function. Nature. 2014; 505:335-343. [PubMed: 24429632]

Frith J, Day CP, Henderson E, Burt AD, Newton JL. Non-alcoholic fatty liver disease in older people. Gerontology. 2009; 55:607-613. [PubMed: 19690397]

Fujita M, Kinoshita T. Structural remodeling of GPI anchors during biosynthesis and after attachment to proteins. FEBS Lett. 2010; 584:1670-1677. [PubMed: 19883648]

Fullerton MD, Hakimuddin F, Bakovic M. Developmental and metabolic effects of disruption of the mouse CTP:phosphoethanolamine cytidylyltransferase gene (Pcyt2). Mol Cell Biol. 2007; 27:3327-3336. [PubMed: 17325045]

Fullerton MD, Hakimuddin F, Bonen A, Bakovic M. The development of a metabolic disease phenotype in CTP:phosphoethanolamine cytidylyltransferase-deficient mice. J Biol Chem. 2009; 284:25704-25713. [PubMed: 19625253]

Futerman AH, Hannun YA. The complex life of simple sphingolipids. EMBO Rep. 2004; 5:777-782. [PubMed: 15289826]

Gaigg B, Simbeni R, Hrastnik C, Paltauf F, Daum G. Characterization of a microsomal subfraction associated with mitochondria of the yeast, Saccharomycescerevisiae. Involvement in synthesis and import of phospholipids into mitochondria. Biochim Biophys Acta. 1995; 1234:214-220. [PubMed: 7696296]

Garcia-Perez C, Schneider TG, Hajnoczky G, Csordas G. Alignment of sarcoplasmic reticulummitochondrial junctions with mitochondrial contact points. Am J Physiol Heart Circ Physiol. 2011; 301:H1907-H1915. [PubMed: 21856920]

Gastaldelli A, Kozakova M, Hojlund K, Flyvbjerg A, Favuzzi A, Mitrakou A, Balkau B. Fatty liver is associated with insulin resistance, risk of coronary heart disease, and early atherosclerosis in a large European population. Hepatology. 2009; 49:1537-1544. [PubMed: 19291789]

Gaynor EC, Mondésert G, Grimme SJ, Reed SI, Orlean P, Emr SD. MCD4 encodes a conserved endoplasmic reticulum membrane protein essential for glycosylphosphatidylinositol anchor synthesis in yeast. Mol Biol Cell. 1999; 10:627-648. [PubMed: 10069808]

Gnamusch E, Kalaus C, Hrastnik C, Paltauf F, Daum G. Transport of phospholipids between subcellular membranes of wild-type yeast cells and of the phosphatidylinositol transfer proteindeficient strain Saccharomycescerevisiae sec 14. Biochim Biophys Acta. 1992; 1111:120-126. [PubMed: 1390857]

Goedert M, Spillantini MG. A century of Alzheimer's disease. Science. 2006; 314:777-781. [PubMed: 17082447]

Gohil VM, Thompson MN, Greenberg ML. Synthetic lethal interaction of the mitochondrial phosphatidylethanolamine and cardiolipin biosynthetic pathways in Saccharomyces cerevisiae. J Biol Chem. 2005; 280:35410-35416. [PubMed: 16036913]

Gottlieb D, Heideman W, Saba JD. The DPL1 gene is involved in mediating the response to nutrient deprivation in Saccharomycescerevisiae. Mol Cell Biol Res Commun. 1999; 1:66-71. [PubMed: 10329480] 
Griparic L, Kanazawa T, van der Bliek AM. Regulation of the mitochondrial dynamin-like protein Opa1 by proteolytic cleavage. J Cell Biol. 2007; 178:757-764. [PubMed: 17709430]

Guardia-Laguarta C, Area-Gomez E, Rub C, Liu Y, Magrane J, Becker D, Voos W, Schon EA, Przedborski S. Alpha-synuclein is localized to mitochondria-associated ER membranes. J Neurosci. 2014; 34:249-259. [PubMed: 24381286]

Gulshan K, Shahi P, Moye-Rowley WS. Compartment-specific synthesis of phosphatidylethanolamine is required for normal heavy metal resistance. Mol Biol Cell. 2010; 21:443-455. [PubMed: 20016005]

Haass C, Selkoe DJ. Soluble protein oligomers in neurodegeneration: lessons from the Alzheimer's amyloid beta-peptide. Nat Rev Mol Cell Biol. 2007; 8:101-112. [PubMed: 17245412]

Hailey DW, Rambold AS, Satpute-Krishnan P, Mitra K, Sougrat R, Kim PK, Lippincott-Schwartz J. Mitochondria supply membranes for autophagosome biogenesis during starvation. Cell. 2010; 141:656-667. [PubMed: 20478256]

Hajnoczky G, Thomas AP. Minimal requirements for calcium oscillations driven by the IP3 receptor. EMBO J. 1997; 16:3533-3543. [PubMed: 9218795]

Hamasaki M, Furuta N, Matsuda A, Nezu A, Yamamoto A, Fujita N, Oomori H, Noda T, Haraguchi T, Hiraoka Y, Amano A, Yoshimori T. Autophagosomes form at ER-mitochondria contact sites. Nature. 2013; 495:389-393. [PubMed: 23455425]

Hanada T, Noda NN, Satomi Y, Ichimura Y, Fujioka Y, Takao T, Inagaki F, Ohsumi Y. The Atg12Atg5 conjugate has a novel E3-like activity for protein lipidation in autophagy. J Biol Chem. 2007; 282:37298-37302. [PubMed: 17986448]

Hannun YA, Obeid LM. Principles of bioactive lipid signalling: lessons from sphingolipids. Nat Rev Mol Cell Biol. 2008; 9:139-150. [PubMed: 18216770]

Harner M, Korner C, Walther D, Mokranjac D, Kaesmacher J, Welsch U, Griffith J, Mann M, Reggiori F, Neupert W. The mitochondrial contact site complex, a determinant of mitochondrial architecture. EMBO J. 2011; 30:4356-4370. [PubMed: 22009199]

Hayashi T, Fujimoto M. Detergent-resistant microdomains determine the localization of sigma-1 receptors to the endoplasmic reticulum-mitochondria junction. Mol Pharmacol. 2010; 77:517528. [PubMed: 20053954]

Hemelaar J, Lelyveld VS, Kessler BM, Ploegh HL. A single protease, Apg4B, is specific for the autophagy-related ubiquitin-like proteins GATE-16, MAP1-LC3, GABARAP, and Apg8L. J Biol Chem. 2003; 278:51841-51850. [PubMed: 14530254]

Herlan M, Bornhövd C, Hell K, Neupert W, Reichert AS. Alternative topogenesis of Mgm1 and mitochondrial morphology depend on ATP and a functional import motor. J Cell Biol. 2004; 165:167-173. [PubMed: 15096522]

Herlan M, Vogel F, Bornhövd C, Neupert W, Reichert AS. Processing of Mgm1 by the rhomboid-type protease Pcp1 is required for maintenance of mitochondrial morphology and of mitochondrial DNA. J Biol Chem. 2003; 278:27781-27788. [PubMed: 12707284]

Hermann GJ, Thatcher JW, Mills JP, Hales KG, Fuller MT, Nunnari J, Shaw JM. Mitochondrial fusion in yeast requires the transmembrane GTPase Fzo1p. J Cell Biol. 1998; 143:359-373. [PubMed: 9786948]

Hjelmstad RH, Bell RM. sn-1,2-diacylglycerol choline- and ethanolaminephosphotransferases in Saccharomycescerevisiae. Mixed micellar analysis of the CPT1 and EPT1 gene products. J Biol Chem. 1991; 266:4357-4365. [PubMed: 1847919]

Hong Y, Maeda Y, Watanabe R, Ohishi K, Mishkind M, Riezman H, Kinoshita T. Pig-n, a mammalian homologue of yeast Mcd4p, is involved in transferring phosphoethanolamine to the first mannose of the glycosylphosphatidylinositol. J Biol Chem. 1999; 274:35099-35106. [PubMed: 10574991]

Honscher C, Mari M, Auffarth K, Bohnert M, Griffith J, Geerts W, van der Laan M, Cabrera M, Reggiori F, Ungermann C. Cellular metabolism regulates contact sites between vacuoles and mitochondria. Dev Cell. 2014; 30:86-94. [PubMed: 25026035]

Hoppins S, Collins SR, Cassidy-Stone A, Hummel E, Devay RM, Lackner LL, Westermann B, Schuldiner M, Weissman JS, Nunnari J. A mitochondrial-focused genetic interaction map reveals a scaffold-like complex required for inner membrane organization in mitochondria. J Cell Biol. 2011; 195:323-340. [PubMed: 21987634] 
Horvath SE, Bottinger L, Vogtle FN, Wiedemann N, Meisinger C, Becker T, Daum G. Processing and topology of the yeast mitochondrial phosphatidylserine decarboxylase 1. J Biol Chem. 2012; 287:36744-36755. [PubMed: 22984266]

Hovius R, Faber B, Brigot B, Nicolay K, de Kruijff B. On the mechanism of the mitochondrial decarboxylation of phosphatidylserine. J Biol Chem. 1992; 267:16790-16795. [PubMed: 1512221]

Hutton M, Perez-Tur J, Hardy J. Genetics of Alzheimer's disease. Essays Biochem. 1998; 33:117-131. [PubMed: 10488446]

Ichimura Y, Kirisako T, Takao T, Satomi Y, Shimonishi Y, Ishihara N, Mizushima N, Tanida I, Kominami E, Ohsumi M, Noda T, Ohsumi Y. A ubiquitin-like system mediates protein lipidation. Nature. 2000; 408:488-492. [PubMed: 11100732]

Ikezawa H. Glycosylphosphatidylinositol (GPI)-anchored proteins. Biol Pharm Bull. 2002; 25:409_ 417. [PubMed: 11995915]

Ishidate K, Furusawa K, Nakazawa Y. Complete co-purification of choline kinase and ethanolamine kinase from rat kidney and immunological evidence for both kinase activities residing on the same enzyme protein(s) in rat tissues. Biochim Biophys Acta. 1985; 836:119-124. [PubMed: 2992596]

Itoh K, Tamura Y, Iijima M, Sesaki H. Effects of Fcj1-Mos1 and mitochondrial division on aggregation of mitochondrial DNA nucleoids and organelle morphology. Mol Biol Cell. 2013; 24:1842-1851. [PubMed: 23615445]

Jain S, Stanford N, Bhagwat N, Seiler B, Costanzo M, Boone C, Oelkers P. Identification of a novel lysophospholipid acyltransferase in Saccharomycescerevisiae. J Biol Chem. 2007; 282:3056230569. [PubMed: 17726007]

Jans DC, Wurm CA, Riedel D, Wenzel D, Stagge F, Deckers M, Rehling Ps, Jakobs S. STED superresolution microscopy reveals an array of MINOS clusters along human mitochondria. Proc Natl Acad Sci USA. 2013; 110:8936-8941. [PubMed: 23676277]

Jiang F, Rizavi HS, Greenberg ML. Cardiolipin is not essential for the growth of Saccharomyces cerevisiae on fermentable or non-fermentable carbon sources. Mol Microbiol. 1997; 26:481-491. [PubMed: 9402019]

Jones BA, Fangman WL. Mitochondrial DNA maintenance in yeast requires a protein containing a region related to the GTP-binding domain of dynamin. Genes Dev. 1992; 6:380-389. [PubMed: 1532158]

Joshi AS, Thompson MN, Fei N, Huttemann M, Greenberg ML. Cardiolipin and mitochondrial phosphatidylethanolamine have overlapping functions in mitochondrial fusion in Saccharomyces cerevisiae. J Biol Chem. 2012; 287:17589-17597. [PubMed: 22433850]

Joshi AS, Zhou J, Gohil VM, Chen S, Greenberg ML. Cellular functions of cardiolipin in yeast. Biochim Biophys Acta. 2009; 1793:212-218. [PubMed: 18725250]

Jung JI, Premraj S, Cruz PE, Ladd TB, Kwak Y, Koo EH, Felsenstein KM, Golde TE, Ran Y. Independent relationship between amyloid precursor protein (APP) dimerization and gammasecretase processivity. PLoS One. 2014; 9:e111553. [PubMed: 25350374]

Kabeya Y, Mizushima N, Ueno T, Yamamoto A, Kirisako T, Noda T, Kominami E, Ohsumi Y, Yoshimori T. LC3, a mammalian homologue of yeast Apg8p, is localized in autophagosome membranes after processing. EMBO J. 2000; 19:5720-5728. [PubMed: 11060023]

Kainu V, Hermansson M, Hanninen S, Hokynar K, Somerharju P. Import of phosphatidylserine to and export of phosphatidylethanolamine molecular species from mitochondria. Biochim Biophys Acta. 2013; 1831:429-437. [PubMed: 23159415]

Kara E, Lewis PA, Ling H, Proukakis C, Houlden H, Hardy J. Alpha-synuclein mutations cluster around a putative protein loop. Neurosci Lett. 2013; 546:67-70. [PubMed: 23669636]

Kennedy EP, Weiss SB. The function of cytidine coenzymes in the biosynthesis of phospholipides. J Biol Chem. 1956; 222:193-214. [PubMed: 13366993]

Kim J, Huang WP, Klionsky DJ. Membrane recruitment of Aut7p in the autophagy and cytoplasm to vacuole targeting pathways requires Aut1p, Aut2p, and the autophagy conjugation complex. J Cell Biol. 2001; 152:51-64. [PubMed: 11149920] 
Kimura N, Nakamura SI, Honda T, Takashima A, Nakayama H, Ono F, Sakakibara I, Doi K, Kawamura S, Yoshikawa Y. Age-related changes in the localization of presenilin-1 in cynomolgus monkey brain. Brain Res. 2001; 922:30-41. [PubMed: 11730699]

Kinoshita T, Fujita M, Maeda Y. Biosynthesis, remodelling and functions of mammalian GPIanchored proteins: recent progress. J Biochem. 2008; 144:287-294. [PubMed: 18635593]

Kirisako T, Baba M, Ishihara N, Miyazawa K, Ohsumi M, Yoshimori T, Noda T, Ohsumi Y. Formation process of autophagosome is traced with Apg8/Aut7p in yeast. J Cell Biol. 1999; 147:435-446. [PubMed: 10525546]

Kirisako T, Ichimura Y, Okada H, Kabeya Y, Mizushima N, Yoshimori T, Ohsumi M, Takao T, Noda $\mathrm{T}$, Ohsumi Y. The reversible modification regulates the membrane-binding state of Apg8/Aut7 essential for autophagy and the cytoplasm to vacuole targeting pathway. J Cell Biol. 2000; 151:263-276. [PubMed: 11038174]

Kitada T, Asakawa S, Hattori N, Matsumine H, Yamamura Y, Minoshima S, Yokochi M, Mizuno Y, Shimizu N. Mutations in the parkin gene cause autosomal recessive juvenile parkinsonism. Nature. 1998; 392:605-608. [PubMed: 9560156]

Klein C, Schlossmacher MG. The genetics of Parkinson disease: Implications for neurological care. Nat Clin Pract Neurol. 2006; 2:136-146. [PubMed: 16932540]

Klein C, Westenberger A. Genetics of Parkinson's disease. Cold Spring Harb Perspect Med. 2012; 2:a008888. [PubMed: 22315721]

Kleiner DE, Brunt EM, Van Natta M, Behling C, Contos MJ, Cummings OW, Ferrell LD, Liu YC, Torbenson MS, Unalp-Arida A, Yeh M, McCullough AJ, Sanyal AJ. Design and validation of a histological scoring system for nonalcoholic fatty liver disease. Hepatology. 2005; 41:13131321. [PubMed: 15915461]

Knoll G, Brdiczka D. Changes in freeze-fractured mitochondrial membranes correlated to their energetic state: Dynamic interactions of the boundary membranes. Biochim Biophys Acta. 1983; 733:102-110. [PubMed: 6882749]

Kodaki T, Yamashita S. Yeast phosphatidylethanolamine methylation pathway. Cloning and characterization of two distinct methyltransferase genes. J Biol Chem. 1987; 262:15428-15435. [PubMed: 2445736]

Kornmann B, Currie E, Collins SR, Schuldiner M, Nunnari J, Weissman JS, Walter P. An ERmitochondria tethering complex revealed by a synthetic biology screen. Science. 2009; 325:477481. [PubMed: 19556461]

Kornmann B, Osman C, Walter P. The conserved GTPase Gem1 regulates endoplasmic reticulummitochondria connections. Proc Natl Acad Sci USA. 2011; 108:14151-14156. [PubMed: 21825164]

Kretzschmar H, Tatzelt J. Prion disease: a tale of folds and strains. Brain Pathol. 2013; 23:321-332. [PubMed: 23587138]

Kruger R, Kuhn W, Muller T, Woitalla D, Graeber M, Kosel S, Przuntek H, Epplen JT, Schols L, Riess O. Ala30Pro mutation in the gene encoding alpha-synuclein in Parkinson's disease. Nat Genet. 1998; 18:106-108. [PubMed: 9462735]

Kuchler K, Daum G, Paltauf F. Subcellular and submitochondrial localization of phospholipidsynthesizing enzymes in Saccharomycescerevisiae. J Bacteriol. 1986; 165:901-910. [PubMed: 3005242]

Kuge O, Nishijima M, Akamatsu Y. Isolation of a somatic-cell mutant defective in phosphatidylserine biosynthesis. Proc Natl Acad Sci USA. 1985; 82:1926-1930. [PubMed: 3856869]

Kuge O, Nishijima M, Akamatsu Y. Phosphatidylserine biosynthesis in cultured Chinese hamster ovary cells. III. Genetic evidence for utilization of phosphatidylcholine and phosphatidylethanolamine as precursors. J Biol Chem. 1986; 261:5795-5798. [PubMed: 3084471]

Kuge O, Nishijima M, Akamatsu Y. A cloned gene encoding phosphatidylserine decarboxylase complements the phosphatidylserine biosynthetic defect of a Chinese hamster ovary cell mutant. J Biol Chem. 1991; 266:6370-6376. [PubMed: 2007589] 
Kuge O, Saito K, Kojima M, Akamatsu Y, Nishijima M. Post-translational processing of the phosphatidylserine decarboxylase gene product in Chinese hamster ovary cells. Biochem J. 1996; 319(Pt 1):33-38. [PubMed: 8870646]

Lahiri S, Chao JT, Tavassoli S, Wong AK, Choudhary V, Young BP, Loewen CJ, Prinz WA. A conserved endoplasmic reticulum membrane protein complex (EMC) facilitates phospholipid transfer from the ER to mitochondria. PLoS Biol. 2014; 12:e1001969. [PubMed: 25313861]

Lammich S, Kojro E, Postina R, Gilbert S, Pfeiffer R, Jasionowski M, Haass C, Fahrenholz F. Constitutive and regulated alpha-secretase cleavage of Alzheimer's amyloid precursor protein by a disintegrin metalloprotease. Proc Natl Acad Sci USA. 1999; 96:3922-3927. [PubMed: 10097139]

Lange C, Nett JH, Trumpower BL, Hunte C. Specific roles of protein-phospholipid interactions in the yeast cytochrome bc1 complex structure. EMBO J. 2001; 20:6591-6600. [PubMed: 11726495]

Lapuente-Brun E, Moreno-Loshuertos R, Acin-Perez R, Latorre-Pellicer A, Colas C, Balsa E, PeralesClemente E, Quiros PM, Calvo E, Rodriguez-Hernandez MA, Navas P, Cruz R, Carracedo A, Lopez-Otin C, Perez-Martos A, Fernandez-Silva P, Fernandez-Vizarra E, Enriquez JA. Supercomplex assembly determines electron flux in the mitochondrial electron transport chain. Science. 2013; 340:1567-1570. [PubMed: 23812712]

Leonardi R, Frank MW, Jackson PD, Rock CO, Jackowski S. Elimination of the CDP-ethanolamine pathway disrupts hepatic lipid homeostasis. J Biol Chem. 2009; 284:27077-27089. [PubMed: 19666474]

Li QX, Dowhan W. Structural characterization of Escherichiacoli phosphatidylserine decarboxylase. J Biol Chem. 1988; 263:11516-11522. [PubMed: 3042771]

Li QX, Dowhan W. Studies on the mechanism of formation of the pyruvate prosthetic group of phosphatidylserine decarboxylase from Escherichia coli. J Biol Chem. 1990; 265:4111-4115. [PubMed: 2406271]

Li Z, Agellon LB, Allen TM, Umeda M, Jewell L, Mason A, Vance DE. The ratio of phosphatidylcholine to phosphatidylethanolamine influences membrane integrity and steatohepatitis. Cell Metab. 2006; 3:321-331. [PubMed: 16679290]

Li Z, Agellon LB, Vance DE. Phosphatidylcholine homeostasis and liver failure. J Biol Chem. 2005; 280:37798-37802. [PubMed: 16144842]

Lortholary O, Renaudat C, Sitbon K, Madec Y, Denoeud-Ndam L, Wolff M, Fontanet A, Bretagne S, Dromer F. Worrisome trends in incidence and mortality of candidemia in intensive care units (Paris area, 2002-2010). Intensive Care Med. 2014; 40:1303-1312. [PubMed: 25097069]

Lu YW, Claypool SM. Disorders of phospholipid metabolism: an emerging class of mitochondrial disease due to defects in nuclear genes. Front Genet. 2015; 6:3. [PubMed: 25691889]

Lykidis A, Jackson P, Jackowski S. Lipid activation of CTP: phosphocholine cytidylyltransferase alpha: characterization and identification of a second activation domain. Biochemistry. 2001; 40:494-503. [PubMed: 11148044]

Mancini A, Del Rosso F, Roberti R, Orvietani P, Coletti L, Binaglia L. Purification of ethanolaminephosphotransferase from bovine liver microsomes. Biochim Biophys Acta. 1999; 1437:80-92. [PubMed: 9931448]

Mannella CA, Buttle K, Rath BK, Marko M. Electron microscopic tomography of rat-liver mitochondria and their interaction with the endoplasmic reticulum. Biofactors. 1998; 8:225-228. [PubMed: 9914823]

Marambaud P, Shioi J, Serban G, Georgakopoulos A, Sarner S, Nagy V, Baki L, Wen P, Efthimiopoulos S, Shao Z, Wisniewski T, Robakis NK. A presenilin-1/ gamma-secretase cleavage releases the E-cadherin intracellular domain and regulates disassembly of adherens junctions. EMBO J. 2002; 21:1948-1956. [PubMed: 11953314]

Mattson MP, Cheng B, Culwell AR, Esch FS, Lieberburg I, Rydel RE. Evidence for excitoprotective and intraneuronal calcium-regulating roles for secreted forms of the beta-amyloid precursor protein. Neuron. 1993; 10:243-254. [PubMed: 8094963]

Maydan G, Noyman I, Har-Zahav A, Neriah ZB, Pasmanik-Chor M, Yeheskel A, Albin-Kaplanski A, Maya I, Magal N, Birk E, Simon AJ, Halevy A, Rechavi G, Shohat M, Straussberg R, Basel- 
Vanagaite L. Multiple congenital anomalies-hypotonia-seizures syndrome is caused by a mutation in PIGN. J Med Genet. 2011; 48:383-389. [PubMed: 21493957]

McQuibban GA, Saurya S, Freeman M. Mitochondrial membrane remodelling regulated by a conserved rhomboid protease. Nature. 2003; 423:537-541. [PubMed: 12774122]

Meisinger C, Rissler M, Chacinska A, Szklarz LK, Milenkovic D, Kozjak V, Schonfisch B, Lohaus C, Meyer HE, Yaffe MP, Guiard B, Wiedemann N, Pfanner N. The mitochondrial morphology protein Mdm10 functions in assembly of the preprotein translocase of the outer membrane. Dev Cell. 2004; 7:61-71. [PubMed: 15239954]

Menon AK, Stevens VL. Phosphatidylethanolamine is the donor of the ethanolamine residue linking a glycosylphosphatidylinositol anchor to protein. J Biol Chem. 1992; 267:15277-15280. [PubMed: 1322394]

Miller MA, Kent C. Characterization of the pathways for phosphatidylethanolamine biosynthesis in Chinese hamster ovary mutant and parental cell lines. J Biol Chem. 1986; 261:9753-9761. [PubMed: 3090025]

Mirbagheri SA, Rashidi A, Abdi S, Saedi D, Abouzari M. Liver: an alarm for the heart? Liver Int. 2007; 27:891-894. [PubMed: 17696926]

Mizushima N, Yamamoto A, Hatano M, Kobayashi Y, Kabeya Y, Suzuki K, Tokuhisa T, Ohsumi Y, Yoshimori T. Dissection of autophagosome formation using Apg5-deficient mouse embryonic stem cells. J Cell Biol. 2001; 152:657-668. [PubMed: 11266458]

Mizushima N, Yoshimori T, Ohsumi Y. The role of Atg proteins in autophagosome formation. Annu Rev Cell Dev Biol. 2011; 27:107-132. [PubMed: 21801009]

Mouritsen OG, Zuckermann MJ. What's so special about cholesterol? Lipids. 2004; 39:1101-1113. [PubMed: 15726825]

Mullan M, Crawford F, Axelman K, Houlden H, Lilius L, Winblad B, Lannfelt L. A pathogenic mutation for probable Alzheimer's disease in the APP gene at the N-terminus of beta-amyloid. Nat Genet. 1992; 1:345-347. [PubMed: 1302033]

Munter LM, Voigt P, Harmeier A, Kaden D, Gottschalk KE, Weise C, Pipkorn R, Schaefer M, Langosch D, Multhaup G. GxxxG motifs within the amyloid precursor protein transmembrane sequence are critical for the etiology of Abeta42. EMBO J. 2007; 26:1702-1712. [PubMed: 17332749]

Nair U, Yen WL, Mari M, Cao Y, Xie Z, Baba M, Reggiori F, Klionsky DJ. A role for Atg8-PE deconjugation in autophagosome biogenesis. Autophagy. 2012; 8:780-793. [PubMed: 22622160]

Nakashima A, Hosaka K, Nikawa J. Cloning of a human cDNA for CTP-phosphoethanolamine cytidylyltransferase by complementation in vivo of a yeast mutant. J Biol Chem. 1997; 272:9567-9572. [PubMed: 9083101]

Nebauer R, Schuiki I, Kulterer B, Trajanoski Z, Daum G. The phosphatidylethanolamine level of yeast mitochondria is affected by the mitochondrial components Oxa1p and Yme1p. FEBS J. 2007; 274:6180-6190. [PubMed: 17976194]

Nelson GJ. Lipid composition of erythrocytes in various mammalian species. Biochim Biophys Acta. 1967; 144:221-232. [PubMed: 6064604]

Nemani VM, Lu W, Berge V, Nakamura K, Onoa B, Lee MK, Chaudhry FA, Nicoll RA, Edwards RH. Increased expression of alpha-synuclein reduces neurotransmitter release by inhibiting synaptic vesicle reclustering after endocytosis. Neuron. 2010; 65:66-79. [PubMed: 20152114]

Nesic I, Guix FX, Vennekens K, Michaki V, Van Veldhoven PP, Feiguin F, De Strooper B, Dotti CG, Wahle T. Alterations in phosphatidylethanolamine levels affect the generation of Abeta. Aging Cell. 2012; 11:63-72. [PubMed: 22023223]

Nguyen TT, Lewandowska A, Choi JY, Markgraf DF, Junker M, Bilgin M, Ejsing CS, Voelker DR, Rapoport TA, Shaw JM. Gem1 and ERMES do not directly affect phosphatidylserine transport from ER to mitochondria or mitochondrial inheritance. Traffic. 2012; 13:880-890. [PubMed: 22409400]

Nilsson I, von Heijne G. Fine-tuning the topology of a polytopic membrane protein: role of positively and negatively charged amino acids. Cell. 1990; 62:1135-1141. [PubMed: 2119256]

Nishijima M, Kuge O, Akamatsu Y. Phosphatidylserine biosynthesis in cultured Chinese hamster ovary cells. I. Inhibition of de novo phosphatidylserine biosynthesis by exogenous 
phosphatidylserine and its efficient incorporation. J Biol Chem. 1986; 261:5784-5789. [PubMed: 3700372]

Noda NN, Fujioka Y, Hanada T, Ohsumi Y, Inagaki F. Structure of the Atg12-Atg5 conjugate reveals a platform for stimulating Atg8-PE conjugation. EMBO Rep. 2013; 14:206-211. [PubMed: 23238393]

Noda T, Matsuura A, Wada Y, Ohsumi Y. Novel system for monitoring autophagy in the yeast Saccharomyces cerevisiae. Biochem Biophys Res Commun. 1995; 210:126-132. [PubMed: 7741731]

Nosjean O, Briolay A, Roux B. Mammalian GPI proteins: sorting, membrane residence and functions. Biochim Biophys Acta. 1997; 1331:153-186. [PubMed: 9325440]

Nozaki M, Ohishi K, Yamada N, Kinoshita T, Nagy A, Takeda J. Developmental abnormalities of glycosylphosphatidylinositol-anchor-deficient embryos revealed by Cre/loxP system. Lab Invest. 1999; 79:293-299. [PubMed: 10092065]

Ohsumi Y. Historical landmarks of autophagy research. Cell Res. 2014; 24:9-23. [PubMed: 24366340]

Ohvo-Rekila H, Ramstedt B, Leppimaki P, Slotte JP. Cholesterol interactions with phospholipids in membranes. Prog Lipid Res. 2002; 41:66-97. [PubMed: 11694269]

Okamoto M, Yoko-o T, Umemura M, Nakayama Ki, Jigami Y. glycosylphosphatidylinositol-anchored proteins are required for the transport of detergent-resistant microdomain-associated membrane proteins Tat2p and Fur4p. J Biol Chem. 2006; 281:4013-4023. [PubMed: 16361252]

Onguka O, Calzada E, Ogunbona OB, Claypool SM. Phosphatidylserine decarboxylase 1 autocatalysis and function does not require a mitochondrial-specific factor. J Biol Chem. 2015

Osman C, Haag M, Potting C, Rodenfels J, Dip PV, Wieland FT, Brugger B, Westermann B, Langer $\mathrm{T}$. The genetic interactome of prohibitins: coordinated control of cardiolipin and phosphatidylethanolamine by conserved regulators in mitochondria. J Cell Biol. 2009; 184:583596. [PubMed: 19221197]

Osman C, Voelker DR, Langer T. Making heads or tails of phospholipids in mitochondria. J Cell Biol. 2011; 192:7-16. [PubMed: 21220505]

Otomo C, Metlagel Z, Takaesu G, Otomo T. Structure of the human ATG12 ATG5 conjugate required for LC3 lipidation in autophagy. Nat Struct Mol Biol. 2013; 20:59-66. [PubMed: 23202584]

Otter-Nilsson M, Hendriks R, Pecheur-Huet EI, Hoekstra D, Nilsson T. Cytosolic ATPases, p97 and NSF, are sufficient to mediate rapid membrane fusion. EMBO J. 1999; 18:2074-2083. [PubMed: 10205162]

Pasternak SH, Bagshaw RD, Guiral M, Zhang S, Ackerley CA, Pak BJ, Callahan JW, Mahuran DJ. Presenilin-1, nicastrin, amyloid precursor protein, and gamma-secretase activity are co-localized in the lysosomal membrane. J Biol Chem. 2003; 278:26687-26694. [PubMed: 12736250]

Pecheur EI, Martin I, Maier O, Bakowsky U, Ruysschaert JM, Hoekstra D. Phospholipid species act as modulators in p97/p47-mediated fusion of Golgi membranes. Biochemistry. 2002; 41:98139823. [PubMed: 12146947]

Pfaller MA, Diekema DJ. Epidemiology of invasive candidiasis: a persistent public health problem. Clin Microbiol Rev. 2007; 20:133-163. [PubMed: 17223626]

Pimplikar SW. Reassessing the amyloid cascade hypothesis of Alzheimer's disease. Int J Biochem Cell Biol. 2009; 41:1261-1268. [PubMed: 19124085]

Polymeropoulos MH, Higgins JJ, Golbe LI, Johnson WG, Ide SE, Di Iorio G, Sanges G, Stenroos ES, Pho LT, Schaffer AA, Lazzarini AM, Nussbaum RL, Duvoisin RC. Mapping of a gene for Parkinson's disease to chromosome 4q21-q23. Science. 1996; 274:1197-1199. [PubMed: 8895469]

Polymeropoulos MH, Lavedan C, Leroy E, Ide SE, Dehejia A, Dutra A, Pike B, Root H, Rubenstein J, Boyer R, Stenroos ES, Chandrasekharappa S, Athanassiadou A, Papapetropoulos T, Johnson WG, Lazzarini AM, Duvoisin RC, Di Iorio G, Golbe LI, Nussbaum RL. Mutation in the alphasynuclein gene identified in families with Parkinson's disease. Science. 1997; 276:2045-2047. [PubMed: 9197268] 
Poston CN, Duong E, Cao Y, Bazemore-Walker CR. Proteomic analysis of lipid raft-enriched membranes isolated from internal organelles. Biochem Biophys Res Commun. 2011; 415:355360. [PubMed: 22037461]

Potting C, Tatsuta T, König T, Haag M, Wai T, Aaltonen Mari J, Langer T. TRIAP1/PRELI complexes prevent apoptosis by mediating intramitochondrial transport of phosphatidic acid. Cell Metab. 2013; 18:287-295. [PubMed: 23931759]

Potting C, Wilmes C, Engmann T, Osman C, Langer T. Regulation of mitochondrial phospholipids by Ups1/PRELI-like proteins depends on proteolysis and Mdm35. EMBO J. 2010; 29:2888-2898. [PubMed: 20657548]

Qi-Takahara Y, Morishima-Kawashima M, Tanimura Y, Dolios G, Hirotani N, Horikoshi Y, Kametani F, Maeda M, Saido TC, Wang R, Ihara Y. Longer forms of amyloid beta protein: implications for the mechanism of intramembrane cleavage by gamma-secretase. J Neurosci. 2005; 25:436-445. [PubMed: 15647487]

Rapizzi E, Pinton P, Szabadkai G, Wieckowski MR, Vandecasteele G, Baird G, Tuft RA, Fogarty KE, Rizzuto R. Recombinant expression of the voltage-dependent anion channel enhances the transfer of $\mathrm{Ca}^{2+}$ microdomains to mitochondria. J Cell Biol. 2002; 159:613-624. [PubMed: 12438411]

Reggiori F, Klionsky DJ. Autophagic processes in yeast: mechanism, machinery and regulation. Genetics. 2013; 194:341-361. [PubMed: 23733851]

Ridgway ND, Vance DE. Purification of phosphatidylethanolamine N-methyl-transferase from rat liver. J Biol Chem. 1987; 262:17231-17239. [PubMed: 3680298]

Riekhof WR, Voelker DR. Uptake and utilization of lyso-phosphatidylethanolamine by Saccharomycescerevisiae. J Biol Chem. 2006; 281:36588-36596. [PubMed: 17015438]

Riekhof WR, Wu J, Gijon MA, Zarini S, Murphy RC, Voelker DR. Lysophosphatidylcholine metabolism in Saccharomyces cerevisiae: the role of P-type ATPases in transport and a broad specificity acyltransferase in acylation. J Biol Chem. 2007a; 282:36853-36861. [PubMed: 17951629]

Riekhof WR, Wu J, Jones JL, Voelker DR. Identification and characterization of the major lysophosphatidylethanolamine acyltransferase in Saccharomyces cerevisiae. J Biol Chem. 2007b; 282:28344-28352. [PubMed: 17652094]

Rietveld AG, Killian JA, Dowhan W, de Kruijff B. Polymorphic regulation of membrane phospholipid composition in Escherichia coli. J Biol Chem. 1993; 268:12427-12433. [PubMed: 8509382]

Ring S, Weyer SW, Kilian SB, Waldron E, Pietrzik CU, Filippov MA, Herms J, Buchholz C, Eckman $\mathrm{CB}$, Korte M, Wolfer DP, Muller UC. The secreted beta-amyloid precursor protein ectodomain APPs alpha is sufficient to rescue the natomical, behavioral, and electrophysiological abnormalities of APP-deficient mice. J Neurosci. 2007; 27:7817-7826. [PubMed: 17634375]

Robertson JD. The molecular structure and contact relationships of cell membranes. Prog Biophys Mol Biol. 1960; 10:343-418. [PubMed: 13742209]

Rockenfeller P, Koska M, Pietrocola F, Minois N, Knittelfelder O, Sica V, Franz J, Carmona-Gutierrez D, Kroemer G, Madeo F. Phosphatidylethanolamine positively regulates autophagy and longevity. Cell Death Differ. 2015; 22:499-508. [PubMed: 25571976]

Ruetz S, Gros P. Phosphatidylcholine translocase: a physiological role for the mdr2 gene. Cell. 1994; 77:1071-1081. [PubMed: 7912658]

Ruiz-Herrera J, Elorza MV, Valentin E, Sentandreu R. Molecular organization of the cell wall of Candida albicans and its relation to pathogenicity. FEMS Yeast Res. 2006; 6:14-29. [PubMed: 16423067]

Ryan MC, Wilson AM, Slavin J, Best JD, Jenkins AJ, Desmond PV. Associations between liver histology and severity of the metabolic syndrome in subjects with nonalcoholic fatty liver disease. Diabetes Care. 2005; 28:1222-1224. [PubMed: 15855597]

Sakoh-Nakatogawa M, Matoba K, Asai E, Kirisako H, Ishii J, Noda NN, Inagaki F, Nakatogawa H, Ohsumi Y. Atg12-Atg5 conjugate enhances E2 activity of Atg3 by rearranging its catalytic site. Nat Struct Mol Biol. 2013; 20:433-439. [PubMed: 23503366]

Santel A, Fuller MT. Control of mitochondrial morphology by a human mitofusin. J Cell Sci. 2001; 114:867-874. [PubMed: 11181170] 
Satre M, Kennedy EP. Identification of bound pyruvate essential for the activity of phosphatidylserine decarboxylase of Escherichia coli. J Biol Chem. 1978; 253:479-483. [PubMed: 338609]

Schagger H, Pfeiffer K. Supercomplexes in the respiratory chains of yeast and mammalian mitochondria. EMBO J. 2000; 19:1777-1783. [PubMed: 10775262]

Schlame M, Haldar D. Cardiolipin is synthesized on the matrix side of the inner membrane in rat liver mitochondria. J Biol Chem. 1993; 268:74-79. [PubMed: 8380172]

Schlame M, Ren M. The role of cardiolipin in the structural organization of mitochondrial membranes. Biochim Biophys Acta. 2009; 1788:2080-2083. [PubMed: 19413994]

Schroeder TE. The contractile ring and furrowing in dividing cells. Ann NY Acad Sci. 1990; 582:7887. [PubMed: 2192604]

Schuiki I, Daum G. Phosphatidylserine decarboxylases, key enzymes of lipid metabolism. IUBMB Life. 2009; 61:151-162. [PubMed: 19165886]

Selkoe DJ. Presenilin, Notch, and the genesis and treatment of Alzheimer's disease. Proc Natl Acad Sci USA. 2001; 98:11039-11041. [PubMed: 11572965]

Sesaki H, Dunn CD, Iijima M, Shepard KA, Yaffe MP, Machamer CE, Jensen RE. Ups1p, a conserved intermembrane space protein, regulates mitochondrial shape and alternative topogenesis of Mgm1p. J Cell Biol. 2006; 173:651-658. [PubMed: 16754953]

Seto-Young D, Chen CC, Wilson TH. Effect of different phospholipids on the reconstitution of two functions of the lactose carrier of Escherichiacoli. J Membr Biol. 1985; 84:259-267. [PubMed: 3897546]

Shiao YJ, Lupo G, Vance JE. Evidence that phosphatidylserine is imported into mitochondria via a mitochondria-associated membrane and that the majority of mitochondrial phosphatidylethanolamine is derived from decarboxylation of phosphatidylserine. J Biol Chem. 1995; 270:11190-11198. [PubMed: 7744750]

Shinzawa-Itoh K, Aoyama H, Muramoto K, Terada H, Kurauchi T, Tadehara Y, Yamasaki A, Sugimura T, Kurono S, Tsujimoto K, Mizushima T, Yamashita E, Tsukihara T, Yoshikawa S. Structures and physiological roles of 13 integral lipids of bovine heart cytochrome c oxidase. EMBO J. 2007; 26:1713-1725. [PubMed: 17332748]

Shoshan-Barmatz V, Zalk R, Gincel D, Vardi N. Subcellular localization of VDAC in mitochondria and ER in the cerebellum. Biochim Biophys Acta. 2004; 1657:105-114. [PubMed: 15238267]

Simmen T, Aslan JE, Blagoveshchenskaya AD, Thomas L, Wan L, Xiang Y, Feliciangeli SF, Hung $\mathrm{CH}$, Crump CM, Thomas G. PACS-2 controls endoplasmic reticulum-mitochondria communication and Bid-mediated apoptosis. EMBO J. 2005; 24:717-729. [PubMed: 15692567]

Singleton AB, Farrer M, Johnson J, Singleton A, Hague S, Kachergus J, Hulihan M, Peuralinna T, Dutra A, Nussbaum R, Lincoln S, Crawley A, Hanson M, Maraganore D, Adler C, Cookson MR, Muenter M, Baptista M, Miller D, Blancato J, Hardy J, Gwinn-Hardy K. Alpha-synuclein locus triplication causes Parkinson's disease. Science. 2003; 302:841. [PubMed: 14593171]

Smirnova E, Griparic L, Shurland DL, van der Bliek AM. Dynamin-related protein Drp1 is required for mitochondrial division in mammalian cells. Mol Biol Cell. 2001; 12:2245-2256. [PubMed: 11514614]

Smit JJM, Schinkel AH, Elferink RPJO, Groen AK, Wagenaar E, van Deemter L, Mol CAAM, Ottenhoff R, van der Lugt NMT, van Roon MA, van der Valk MA, Offerhaus GJA, Berns AJM, Borst P. Homozygous disruption of the murine MDR2 P-glycoprotein gene leads to a complete absence of phospholipid from bile and to liver disease. Cell. 1993; 75:451-462. [PubMed: 8106172]

Sogo LF, Yaffe MP. Regulation of mitochondrial morphology and inheritance by Mdm10p, a protein of the mitochondrial outer membrane. J Cell Biol. 1994; 126:1361-1373. [PubMed: 8089171]

Song Z, Chen H, Fiket M, Alexander C, Chan DC. OPA1 processing controls mitochondrial fusion and is regulated by mRNA splicing, membrane potential, and Yme1L. J Cell Biol. 2007; 178:749755. [PubMed: 17709429]

Spillantini MG, Schmidt ML, Lee VM, Trojanowski JQ, Jakes R, Goedert M. Alpha-synuclein in Lewy bodies. Nature. 1997; 388:839-840. [PubMed: 9278044] 
Steenbergen R, Nanowski TS, Beigneux A, Kulinski A, Young SG, Vance JE. Disruption of the phosphatidylserine decarboxylase gene in mice causes embryonic lethality and mitochondrial defects. J Biol Chem. 2005; 280:40032-40040. [PubMed: 16192276]

Stevens TJ, Arkin IT. Do more complex organisms have a greater proportion of membrane proteins in their genomes? Proteins. 2000; 39:417-420. [PubMed: 10813823]

Stone SJ, Cui Z, Vance JE. Cloning and expression of mouse liver phosphatidylserine synthase-1 cDNA. Overexpression in rat hepatoma cells inhibits the CDP-ethanolamine pathway for phosphatidylethanolamine biosynthesis. J Biol Chem. 1998; 273:7293-7302. [PubMed: 9516423]

Stone SJ, Vance JE. Cloning and expression of murine liver phosphatidylserine synthase (PSS)-2: differential regulation of phospholipid metabolism by PSS1 and PSS2. Biochem J. 1999; 342(Pt 1):57-64. [PubMed: 10432300]

Stone SJ, Vance JE. Phosphatidylserine synthase-1 and -2 are localized to mitochondria-associated membranes. J Biol Chem. 2000; 275:34534-34540. [PubMed: 10938271]

Storey MK, Clay KL, Kutateladze T, Murphy RC, Overduin M, Voelker DR. Phosphatidylethanolamine has an essential role in Saccharomycescerevisiae that is independent of its ability to form hexagonal phase structures. J Biol Chem. 2001; 276:48539-48548. [PubMed: 11602607]

Sturbois-Balcerzak B, Stone SJ, Sreenivas A, Vance JE. Structure and expression of the murine phosphatidylserine synthase-1 gene. J Biol Chem. 2001; 276:8205-8212. [PubMed: 11084049]

Sud M, Fahy E, Cotter D, Brown A, Dennis EA, Glass CK, Merrill AH Jr, Murphy RC, Raetz CR, Russell DW, Subramaniam S. LMSD: LIPID MAPS structure database. Nucleic Acids Res. 2007; 35:D527-D532. [PubMed: 17098933]

Sundler R. Ethanolaminephosphate cytidylyltransferase. Purification and characterization of the enzyme from rat liver. J Biol Chem. 1975; 250:8585-8590. [PubMed: 241749]

Sundler R, Akesson B. Biosynthesis of phosphatidylethanolamines and phosphatidylcholines from ethanolamine and choline in rat liver. Biochem J. 1975a; 146:309-315. [PubMed: 168873]

Sundler R, Akesson B. Regulation of phospholipid biosynthesis in isolated rat hepatocytes. Effect of different substrates. J Biol Chem. 1975b; 250:3359-3367. [PubMed: 1123345]

Sundler R, Akesson B, Nilsson A. Quantitative role of base exchange in phosphatidylethanolamine synthesis in isolated rat hepatocytes. FEBS Lett. 1974; 43:303-307. [PubMed: 4213338]

Suzuki TT, Kanfer JN. Purification and properties of an ethanolamine-serine base exchange enzyme of rat brain microsomes. J Biol Chem. 1985; 260:1394-1399. [PubMed: 3918039]

Szabadkai G, Bianchi K, Varnai P, De Stefani D, Wieckowski MR, Cavagna D, Nagy AI, Balla T, Rizzuto R. Chaperone-mediated coupling of endoplasmic reticulum and mitochondrial $\mathrm{Ca}^{2+}$ channels. J Cell Biol. 2006; 175:901-911. [PubMed: 17178908]

Takeda J, Miyata T, Kawagoe K, Iida Y, Endo Y, Fujita T, Takahashi M, Kitani T, Kinoshita T. Deficiency of the GPI anchor caused by a somatic mutation of the PIG-A gene in paroxysmal nocturnal hemoglobinuria. Cell. 1993; 73:703-711. [PubMed: 8500164]

Tamaki H, Shimada A, Ito Y, Ohya M, Takase J, Miyashita M, Miyagawa H, Nozaki H, Nakayama R, Kumagai H. LPT1 encodes a membrane-bound O-acyltransferase involved in the acylation of lysophospholipids in the yeast Saccharomycescerevisiae. J Biol Chem. 2007; 282:34288-34298. [PubMed: 17890783]

Tamura Y, Endo T, Iijima M, Sesaki H. Ups1p and Ups2p antagonistically regulate cardiolipin metabolism in mitochondria. J Cell Biol. 2009; 185:1029-1045. [PubMed: 19506038]

Tamura Y, Harada Y, Nishikawa S, Yamano K, Kamiya M, Shiota T, Kuroda T, Kuge O, Sesaki H, Imai K, Tomii K, Endo T. Tam41 is a CDP-diacylglycerol synthase required for cardiolipin biosynthesis in mitochondria. Cell Metab. 2013; 17:709-718. [PubMed: 23623749]

Tamura Y, Iijima M, Sesaki H. Mdm35p imports Ups proteins into the mitochondrial intermembrane space by functional complex formation. EMBO J. 2010; 29:2875-2887. [PubMed: 20622808]

Tamura Y, Onguka O, Hobbs AE, Jensen RE, Iijima M, Claypool SM, Sesaki H. Role for two conserved intermembrane space proteins, Ups1p and Ups2p, [corrected] in intra-mitochondrial phospholipid trafficking. J Biol Chem. 2012a; 287:15205-15218. [PubMed: 22403410] 
Tamura Y, Onguka O, Itoh K, Endo T, Iijima M, Claypool SM, Sesaki H. Phosphatidylethanolamine biosynthesis in mitochondria: phosphatidylserine (PS) trafficking is independent of a PS decarboxylase and intermembrane space proteins UPS1P and UPS2P. J Biol Chem. 2012b; 287:43961-43971. [PubMed: 23124206]

Tanida I, Tanida-Miyake E, Ueno T, Kominami E. The human homolog of Saccharomyces cerevisiae Apg7p is a Protein-activating enzyme for multiple substrates including human Apg12p, GATE-16, GABARAP, and MAP-LC3. J Biol Chem. 2001; 276:1701-1706. [PubMed: 11096062]

Tanzi RE, Bertram L. Twenty years of the Alzheimer's disease amyloid hypothesis: a genetic perspective. Cell. 2005; 120:545-555. [PubMed: 15734686]

Tasseva G, Bai HD, Davidescu M, Haromy A, Michelakis E, Vance JE. Phosphatidylethanolamine deficiency in mammalian mitochondria impairs oxidative phosphorylation and alters mitochondrial morphology. J Biol Chem. 2013; 288:4158-4173. [PubMed: 23250747]

Thomas E, Roman E, Claypool S, Manzoor N, Pla J, Panwar SL. Mitochondria influence CDR1 efflux pump activity, Hog1-mediated oxidative stress pathway, iron homeostasis, and ergosterol levels in Candida albicans. Antimicrob Agents Chemother. 2013; 57:5580-5599. [PubMed: 23979757]

Tijburg LB, Geelen MJ, Van Golde LM. Biosynthesis of phosphatidylethanolamine via the CDPethanolamine route is an important pathway in isolated rat hepatocytes. Biochem Biophys Res Commun. 1989; 160:1275-1280. [PubMed: 2499328]

Tijburg LB, Houweling M, Geelen JH, van Golde LM. Stimulation of phosphatidylethanolamine synthesis in isolated rat hepatocytes by phorbol 12-myristate 13-acetate. Biochim Biophys Acta. 1987; 922:184-190. [PubMed: 2823905]

Tooze SA, Yoshimori T. The origin of the autophagosomal membrane. Nat Cell Biol. 2010; 12:831835. [PubMed: 20811355]

Trotter PJ, Pedretti J, Voelker DR. Phosphatidylserine decarboxylase from Saccharomyces cerevisiae. Isolation of mutants, cloning of the gene, and creation of a null allele. J Biol Chem. 1993; 268:21416-21424. [PubMed: 8407984]

Trotter PJ, Pedretti J, Yates R, Voelker DR. Phosphatidylserine decarboxylase 2 of Saccharomycescerevisiae. Cloning and mapping of the gene, heterologous expression, and creation of the null allele. J Biol Chem. 1995; 270:6071-6080. [PubMed: 7890740]

Trotter PJ, Voelker DR. Identification of a non-mitochondrial phosphatidylserine decarboxylase activity (PSD2) in the yeast Saccharomyces cerevisiae. J Biol Chem. 1995; 270:6062-6070. [PubMed: 7890739]

Tuller G, Hrastnik C, Achleitner G, Schiefthaler U, Klein F, Daum G. YDL142c encodes cardiolipin synthase (Cls1p) and is non-essential for aerobic growth of Saccharomycescerevisiae. FEBS Lett. 1998; 421:15-18. [PubMed: 9462830]

Tuyama AC, Chang CY. Non-alcoholic fatty liver disease. J Diabetes. 2012; 4:266-280. [PubMed: 22564417]

Twig G, Shirihai OS. The Interplay Between Mitochondrial Dynamics and Mitophagy. Antioxidants Redox Signaling. 2010; 14:1939-1951. [PubMed: 21128700]

Uchiyama T, Ikeuchi T, Ouchi Y, Sakamoto M, Kasuga K, Shiga A, Suzuki M, Ito M, Atsumi T, Shimizu T, Ohashi T. Prominent psychiatric symptoms and glucose hypometabolism in a family with a SNCA duplication. Neurology. 2008; 71:1289-1291. [PubMed: 18852445]

Ueda Y, Yamaguchi R, Ikawa M, Okabe M, Morii E, Maeda Y, Kinoshita T. PGAP1 knock-out mice show otocephaly and male infertility. J Biol Chem. 2007; 282:30373-30380. [PubMed: 17711852]

Van Deenen, LLM.; De Gier, J. The Red Blood Cell. Vol. 1. Academic Press Inc.; New York, New York: 1974. Lipids of the red cell membrane; p. 147-211.

van den Brink-van der Laan E, Killian JA, de Kruijff B. Nonbilayer lipids affect peripheral and integral membrane proteins via changes in the lateral pressure profile. Biochim Biophys Acta. 2004; 1666:275-288. [PubMed: 15519321]

van der Bliek AM, Shen Q, Kawajiri S. Mechanisms of mitochondrial fission and fusion. Cold Spring Harb Perspect Biol. 2013; 5 
van der Veen JN, Lingrell S, da Silva RP, Jacobs RL, Vance DE. The concentration of phosphatidylethanolamine in mitochondria can modulate ATP production and glucose metabolism in mice. Diabetes. 2014; 63:2620-2630. [PubMed: 24677714]

van Golde LM, Raben J, Batenburg JJ, Fleischer B, Zambrano F, Fleischer S. Biosynthesis of lipids in golgi complex and other subcellular fractions from rat liver. Biochim Biophys Acta. 1974; 360:179-192. [PubMed: 4425464]

van Hellemond JJ, Slot JW, Geelen MJ, van Golde LM, Vermeulen PS. Ultrastructural localization of CTP:phosphoethanolamine cytidylyltransferase in rat liver. J Biol Chem. 1994; 269:1541515418. [PubMed: 8195180]

van Poelje PD, Snell EE. Pyruvoyl-dependent enzymes. Annu Rev Biochem. 1990; 59:29-59. [PubMed: 2197977]

Vance DE, Van den Bosch H. Cholesterol in the year 2000. Biochim Biophys Acta. 2000; 1529:1-8. [PubMed: 11111073]

Vance JE. Phospholipid synthesis in a membrane fraction associated with mitochondria. J Biol Chem. 1990; 265:7248-7256. [PubMed: 2332429]

Vance JE. Newly made phosphatidylserine and phosphatidylethanolamine are preferentially translocated between rat liver mitochondria and endoplasmic reticulum. J Biol Chem. 1991; 266:89-97. [PubMed: 1898727]

Vance JE. MAM (mitochondria-associated membranes) in mammalian cells: lipids and beyond. Biochim Biophys Acta. 2014; 1841:595-609. [PubMed: 24316057]

Vance JE. Phospholipid synthesis and transport in mammalian cells. Traffic. 2015; 16:1-18. [PubMed: 25243850]

Vassar R, Bennett BD, Babu-Khan S, Kahn S, Mendiaz EA, Denis P, Teplow DB, Ross S, Amarante P, Loeloff R, Luo Y, Fisher S, Fuller J, Edenson S, Lile J, Jarosinski MA, Biere AL, Curran E, Burgess T, Louis JC, Collins F, Treanor J, Rogers G, Citron M. Beta-secretase cleavage of Alzheimer's amyloid precursor protein by the transmembrane aspartic protease BACE. Science. 1999; 286:735-741. [PubMed: 10531052]

Verkleij AJ, Leunissen-Bijvelt J, de Kruijff B, Hope M, Cullis PR. Non-bilayer structures in membrane fusion. Ciba Found Symp. 1984; 103:45-59. [PubMed: 6561137]

Vetrivel KS, Cheng H, Lin W, Sakurai T, Li T, Nukina N, Wong PC, Xu H, Thinakaran G. Association of gamma-secretase with lipid rafts in post-golgi and endosome membranes. J Biol Chem. 2004; 279:44945-44954. [PubMed: 15322084]

Voelker DR. Phosphatidylserine functions as the major precursor of phosphatidylethanolamine in cultured BHK-21 cells. Proc Natl Acad Sci USA. 1984; 81:2669-2673. [PubMed: 6425837]

Voelker DR. Disruption of phosphatidylserine translocation to the mitochondria in baby hamster kidney cells. J Biol Chem. 1985; 260:14671-14676. [PubMed: 2997219]

Voelker DR. Phosphatidylserine translocation to the mitochondrion is an ATP-dependent process in permeabilized animal cells. Proc Natl Acad Sci USA. 1989a; 86:9921-9925. [PubMed: 2602382]

Voelker DR. Reconstitution of phosphatidylserine import into rat liver mitochondria. J Biol Chem. 1989b; 264:8019-8025. [PubMed: 2542259]

Voelker DR. Characterization of phosphatidylserine synthesis and translocation in permeabilized animal cells. J Biol Chem. 1990; 265:14340-14346. [PubMed: 2117609]

von der Malsburg K, Muller JM, Bohnert M, Oeljeklaus S, Kwiatkowska P, Becker T, LoniewskaLwowska A, Wiese S, Rao S, Milenkovic D, Hutu DP, Zerbes RM, Schulze-Specking A, Meyer HE, Martinou JC, Rospert S, Rehling P, Meisinger C, Veenhuis M, Warscheid B, van der Klei IJ, Pfanner N, Chacinska A, van der Laan M. Dual role of mitofilin in mitochondrial membrane organization and protein biogenesis. Dev Cell. 2011; 21:694-707. [PubMed: 21944719]

Voss C, Lahiri S, Young BP, Loewen CJ, Prinz WA. ER-shaping proteins facilitate lipid exchange between the ER and mitochondria in S. cerevisiae. J Cell Sci. 2012; 125:4791-4799. [PubMed: 22797914]

Walkey CJ, Yu L, Agellon LB, Vance DE. Biochemical and evolutionary significance of phospholipid methylation. J Biol Chem. 1998; 273:27043-27046. [PubMed: 9765216]

Wang S, Zhang S, Liou LC, Ren Q, Zhang Z, Caldwell GA, Caldwell KA, Witt SN. Phosphatidylethanolamine deficiency disrupts alpha-synuclein homeostasis in yeast and worm 
models of Parkinson disease. Proc Natl Acad Sci USA. 2014; 111:E3976-E3985. [PubMed: 25201965]

Williams CD, Stengel J, Asike MI, Torres DM, Shaw J, Contreras M, Landt CL, Harrison SA. Prevalence of nonalcoholic fatty liver disease and nonalcoholic steatohepatitis among a largely middle-aged population utilizing ultrasound and liver biopsy: a prospective study.

Gastroenterology. 2011; 140:124-131. [PubMed: 20858492]

Wilson-Zbinden C, Dos Santos AX, Stoffel-Studer I, van der Vaart A, Hofmann K, Reggiori F, Riezman H, Kraft C, Peter M. Autophagy competes for a common phosphatidylethanolamine pool with major cellular PE-consuming pathways in Saccharomycescerevisiae. Genetics. 2015; 199:475-485. [PubMed: 25519895]

Wirtz KW, Zilversmit DB. Exchange of phospholipids between liver mitochondria and microsomes invitro. J Biol Chem. 1968; 243:3596-3602. [PubMed: 4968799]

Wittenberg J, Kornberg A. Choline phosphokinase. J Biol Chem. 1953; 202:431-444. [PubMed: 13061469]

Wolfe MS, Xia W, Ostaszewski BL, Diehl TS, Kimberly WT, Selkoe DJ. Two transmembrane aspartates in presenilin-1 required for presenilin endoproteolysis and gamma-secretase activity. Nature. 1999; 398:513-517. [PubMed: 10206644]

Xie Z, Nair U, Klionsky DJ. Atg8 controls phagophore expansion during autophagosome formation. Mol Biol Cell. 2008; 19:3290-3298. [PubMed: 18508918]

Yet SF, Lee S, Hahm YT, Sul HS. Expression and identification of p90 as the murine mitochondrial glycerol-3-phosphate acyltransferase. Biochemistry. 1993; 32:9486-9491. [PubMed: 8369314]

Youngman MJ, Hobbs AE, Burgess SM, Srinivasan M, Jensen RE. Mmm2p, a mitochondrial outer membrane protein required for yeast mitochondrial shape and maintenance of mtDNA nucleoids. J Cell Biol. 2004; 164:677-688. [PubMed: 14981098]

Zarranz JJ, Alegre J, Gomez-Esteban JC, Lezcano E, Ros R, Ampuero I, Vidal L, Hoenicka J, Rodriguez O, Atares B, Llorens V, Gomez Tortosa E, del Ser T, Munoz DG, de Yebenes JG. The new mutation, E46K, of alpha-synuclein causes Parkinson and Lewy body dementia. Ann Neurol. 2004; 55:164-173. [PubMed: 14755719]

Zborowski J, Dygas A, Wojtczak L. Phosphatidylserine decarboxylase is located on the external side of the inner mitochondrial membrane. FEBS Lett. 1983; 157:179-182. [PubMed: 6862014]

Zelinski TA, Choy PC. Phosphatidylethanolamine biosynthesis in isolated hamster heart. Can J Biochem. 1982; 60:817-823. [PubMed: 7127187]

Zhang W, Bogdanov M, Pi J, Pittard AJ, Dowhan W. Reversible topological organization within a polytopic membrane protein is governed by a change in membrane phospholipid composition. $\mathrm{J}$ Biol Chem. 2003; 278:50128-50135. [PubMed: 14525982]

Zhang W, Campbell HA, King SC, Dowhan W. Phospholipids as determinants of membrane protein topology. Phosphatidylethanolamine is required for the proper topological organization of the gamma-aminobutyric acid permease (GabP) of Escherichia coli. J Biol Chem. 2005; 280:2603226038. [PubMed: 15890647]

Zhong Q, Gohil VM, Ma L, Greenberg ML. Absence of cardiolipin results in temperature sensitivity, respiratory defects, and mitochondrial DNA instability independent of pet56. J Biol Chem. 2004; 279:32294-32300. [PubMed: 15169766]

Zhou J, Saba JD. Identification of the first mammalian sphingosine phosphate lyase gene and its functional expression in yeast. Biochem Biophys Res Commun. 1998; 242:502-507. [PubMed: 9464245]

Zick M, Duvezin-Caubet S, Schäfer A, Vogel F, Neupert W, Reichert AS. Distinct roles of the two isoforms of the dynamin-like GTPase Mgm1 in mitochondrial fusion. FEBS Lett. 2009; 583:2237-2243. [PubMed: 19505460]

Zinser E, Sperka-Gottlieb CD, Fasch EV, Kohlwein SD, Paltauf F, Daum G. Phospholipid synthesis and lipid composition of subcellular membranes in the unicellular eukaryote Saccharomycescerevisiae. J Bacteriol. 1991; 173:2026-2034. [PubMed: 2002005] 
(A)

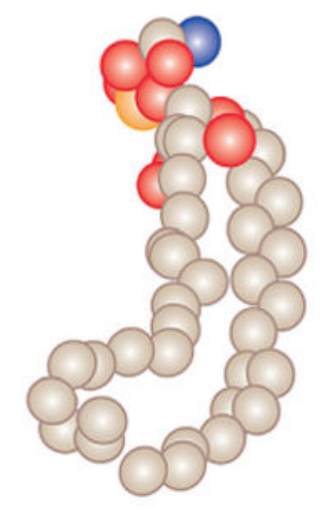

Phosphatidylethanolamine
(B)

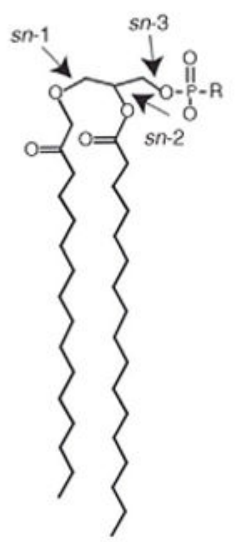

sn-3 R headgroup

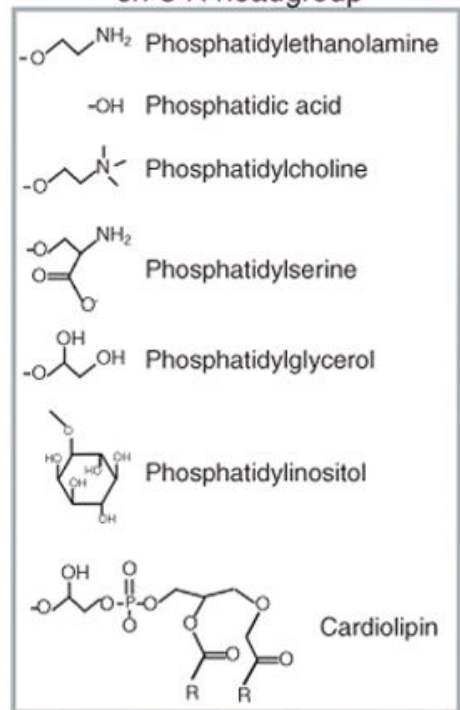

Figure 1.

The glycerophospholipids. (A) Diagram of phosphatidylethanolamine structure. The spheres represent different atoms present in the phospholipid structure tan: carbon, red: oxygen, orange: phosphate, and blue: nitrogen (hydrogen atoms are not represented). (B) General glycerophospholipid structure. Fatty acids are linked to the glycerol backbone at the sn-1 and $s n-2$ positions while the phosphate headgroup is linked at the $s n-3$ position. Different variations of headgroups are shown (for cardiolipin, $\mathrm{R}$ indicates additional acyl groups attached at these positions). 


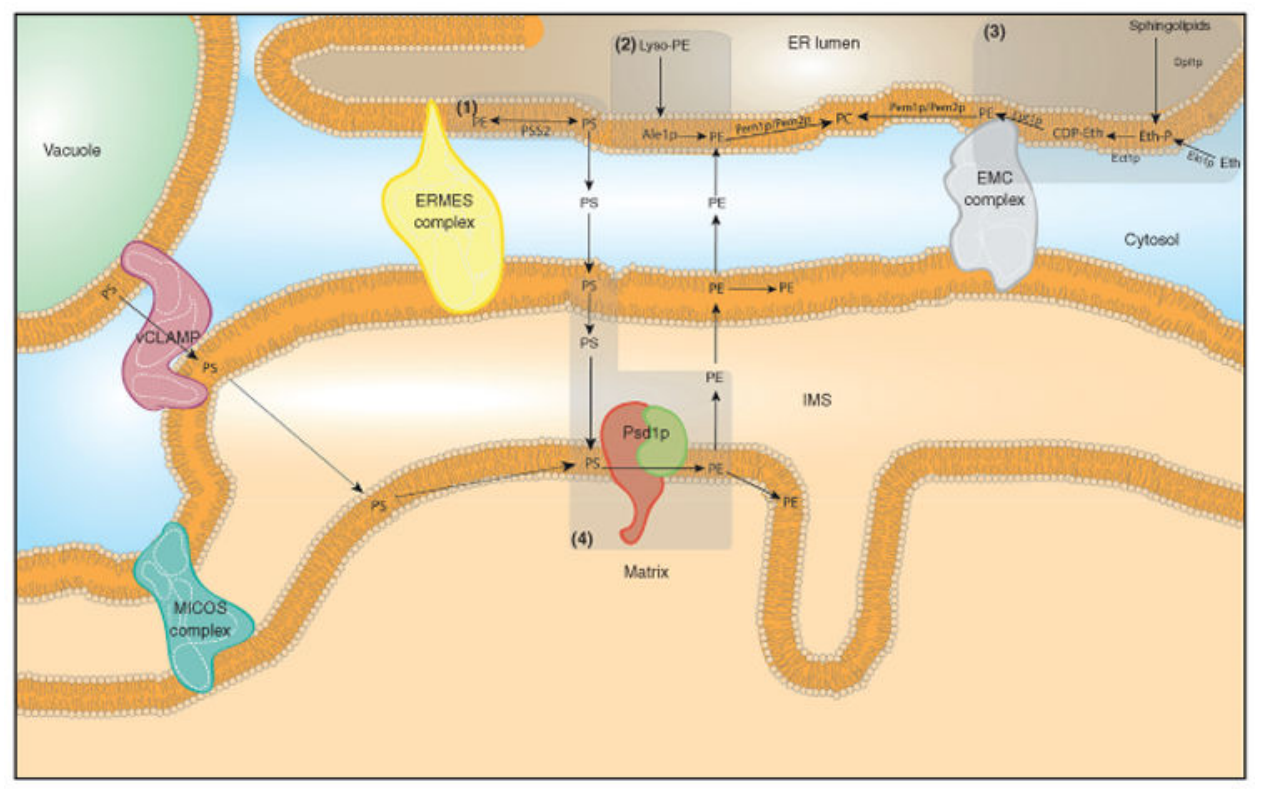

Figure 2.

PE biosynthetic pathways at the ER-mitochondria interface in yeast. (1) Base exchange pathway. In the biosynthesis of PS, head group exchange with PE is mediated by PSS2 in mammals. The reverse reaction can also synthesize PE from PS in small amounts. In yeast, calcium mediates base exchange between PS and PE through poorly understood mechanisms. (2) Acylation of lyso-PE to PE. Ale1p is an acyl transferase that facilitates the conversion of lyso-PE to PE. (3) CDP-ethanolamine pathway or Kennedy pathway. Phosphoethanolamine (Eth-P) is generated by phosphorylation of ethanolamine (Eth) by ethanolamine kinase (Ek1p) or through degradation of sphingolipids by Dpl1p. Phosphoethanolamine and CTP are metabolized by CTP:phosphoethanolamine cytidylyltransferase (Ect1p in yeast, ET in mammals) to generate CDP-ethanolamine (CDPEth), which with 1,2-diacylglycerol ethanolamine phosphotransferase (Ept1p in yeast, ETP in mammals) undergoes a condensation reaction with DAG to form the final product, PE. (4) Phosphatidylserine decarboxylase pathway. Upon its synthesis, PS is transported from the MAM of the ER to the OM of mitochondria until it reaches the IM where Psd1p is located. EMC and ERMES may facilitate transfer of PS to the OM. The OM and IM of mitochondria are tethered by mitochondrial contact site and cristae organizing system (MICOS) structures (please refer to text for mammalian proteins that also serve tethering functions).

Alternatively, PS can be transferred to mitochondrial membranes through the yeast vacoule facilitated by v-CLAMP membrane tethers. In the enzymatic step, Psd1p decarboxylates PS to generate $\mathrm{PE}$ that is integrated in mitochondrial membranes or exported to other locations in the cell. PE generated by any of these pathways can be converted to PC through the action of PE methyltransferases (Pem1p/Pem2p in yeast or PEMT in mammals). 


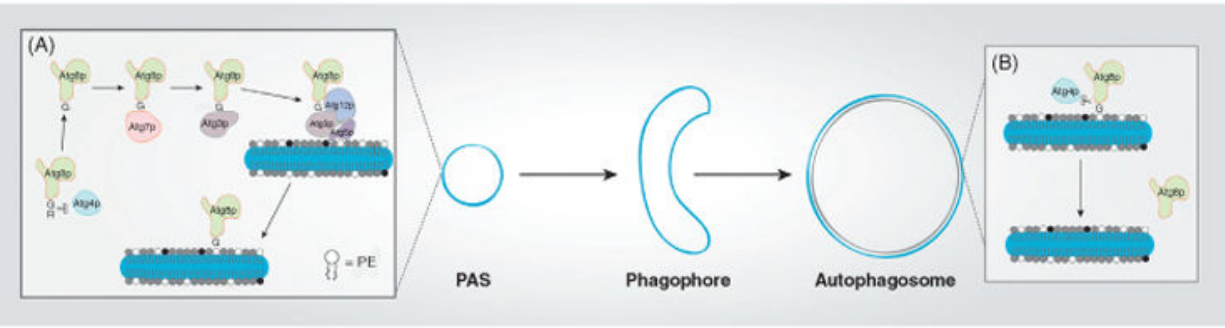

Figure 3.

Atg8p lipidation in yeast. (A) Atg8p is proteolytically processed by the cysteine-protease Atg4p, which removes the $\mathrm{C}$-terminal arginine residue and exposes a critical glycine that is recognized by Atg7p. Atg7p transfers Atg8p to Atg3p that together with the Atg12p-Atg5p protein complex conjugates Atg8p to PE. Atg8p is tethered via PE to membranes on the preautophagosomal structure (PAS) as it expands to the phagophore membrane. The phagophore membrane increases in size as it surrounds its cellular cargo to form a mature autophagosome. (B) When the autophagosome has reached its target size, Atg8p is cleaved at its terminal glycine residue by Atg4p. Similar mechanisms have been observed for LC3 lipidation using the ATG machinery in mammals. 
(A)

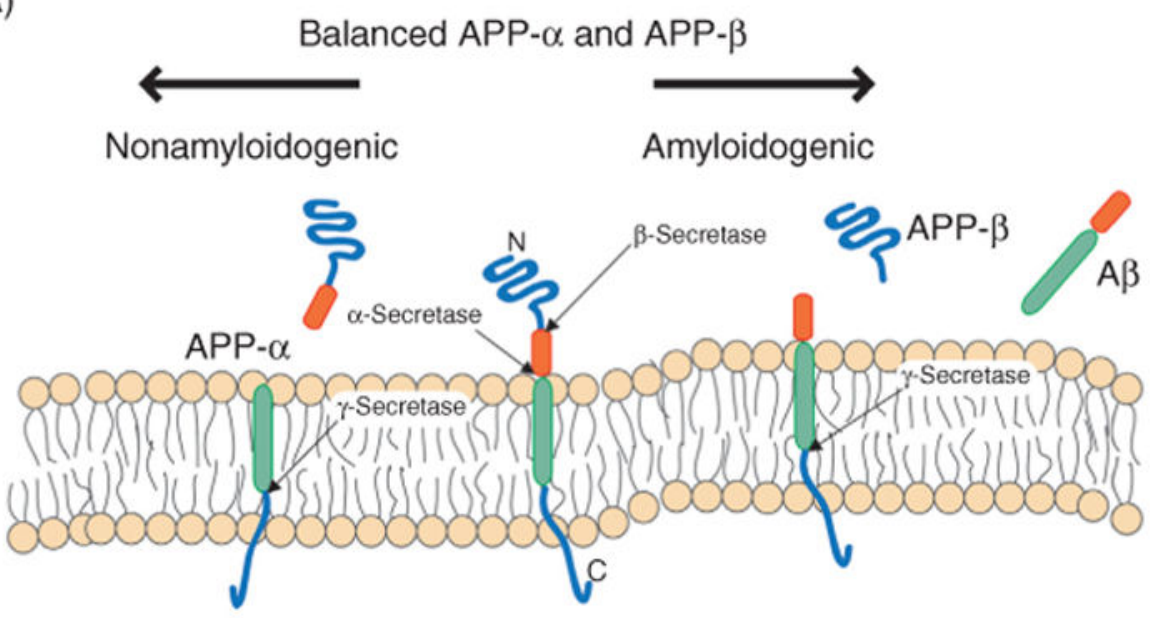

(B)

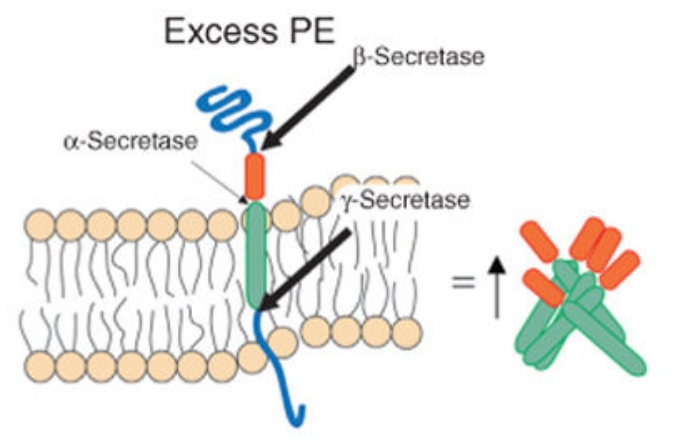

(C)

\section{PE limiting}

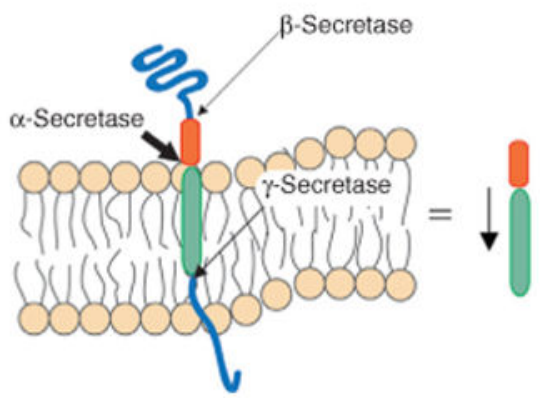

Figure 4.

Alzheimer's disease. Schematic representation of amyloidogenic and nonamyloidogenic processing of APP. (A) Under physiologic conditions, APP is processed by both the $\mathrm{a}$ - and $\beta$-secretases, each event followed by cleavage by $\gamma$-secretase, and an equilibrium exists in which $\mathrm{A} \beta$ aggregates do not accumulate. (B) However, when there is excess PE, $\beta$ - and $\gamma$ secretase activity is increased, which shifts the equilibrium toward the amyloidogenic pathway thus driving the accumulation and aggregation of $A \beta$. (C) In contrast, when PE is limiting (i.e., $p s d l \Delta$ yeast), a-secretase activity is increased thus promoting the nonamyloidogenic pathway. How PE mechanistically alters the activity of the assorted secretases is presently unclear. The thickness of the arrows indicates the relative activity of a particular enzyme. APP- $\alpha$ is a cleavage product of $\alpha$-secretase; APP- $\beta$ is a cleavage product of $\beta$-secretase. 
(A)
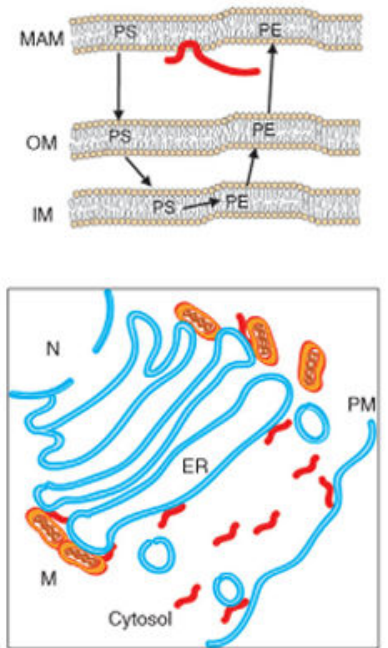

Healthy mitochondria and ER $\alpha$-Synuclein in cytosol, PMs> MAM No $\alpha$-synuclein toxicity
(B)
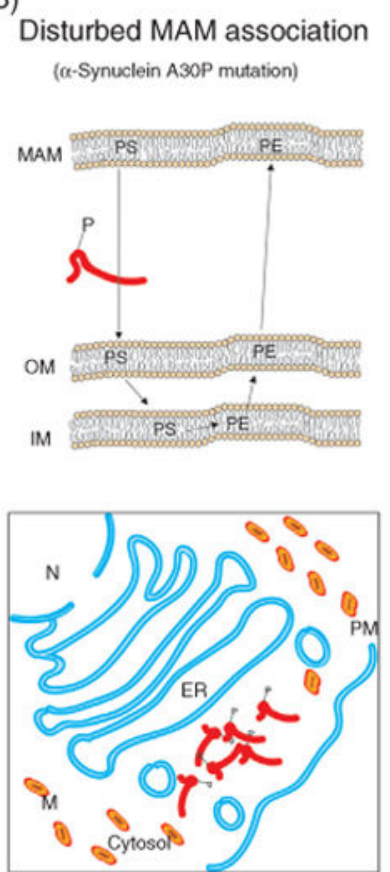

Mitochondrial fragmentation $\alpha$-Synuclein in cytosol s> PM, MAM Increased $\alpha$-synuclein toxicity
(C)

Decreased PE (psd1s)
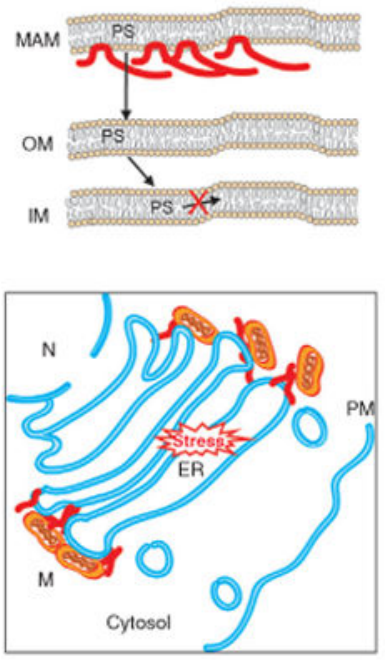

ER stress

$\alpha$-Synuclein in MAM >> PM Increased $\alpha$-synuclein toxicity

Figure 5.

Parkinson's disease. The role of a-synuclein at the MAM and how disturbances in this association impact cell function. (A) Under physiologic conditions, a-synuclein is natively unfolded and found primarily in the cytoplasm or associated with the plasma membrane, but a small fraction associates with the MAM where it supports full mitochondrial function. (B) Mutations that affect $a$-synuclein membrane association prevent its association with the MAM, drive its cytosolic accumulation and aggregation, and induce mitochondrial fragmentation. (C) When PE levels become limiting, a-synuclein accumulates at the MAM leading to ER stress and cytotoxicity. Relative activity is reflected by the thickness of the arrows. N, Nucleus; M, mitochondria; PM, plasma membrane. 
(A)

Healthy liver

(C)
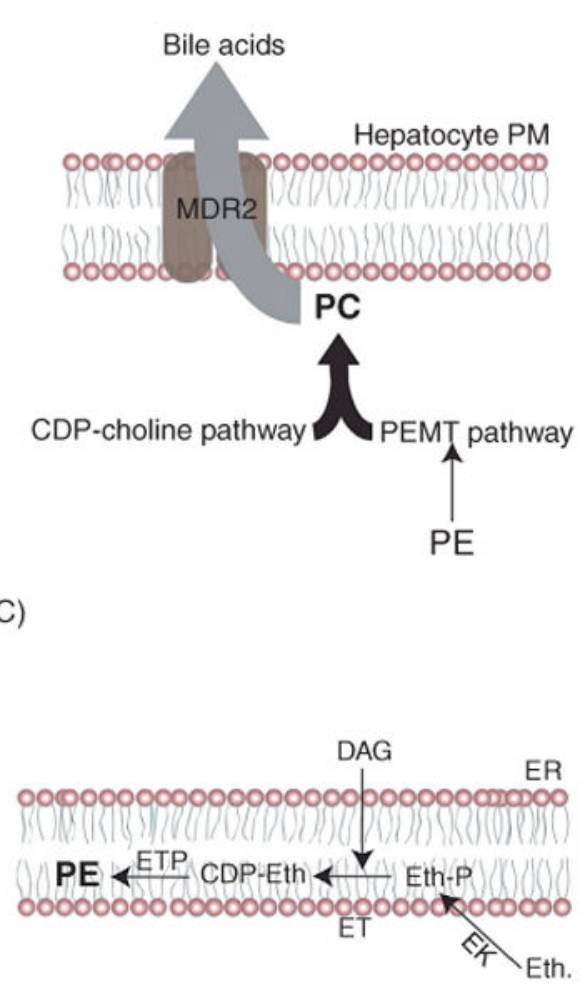

(B)

\section{Fatty liver}

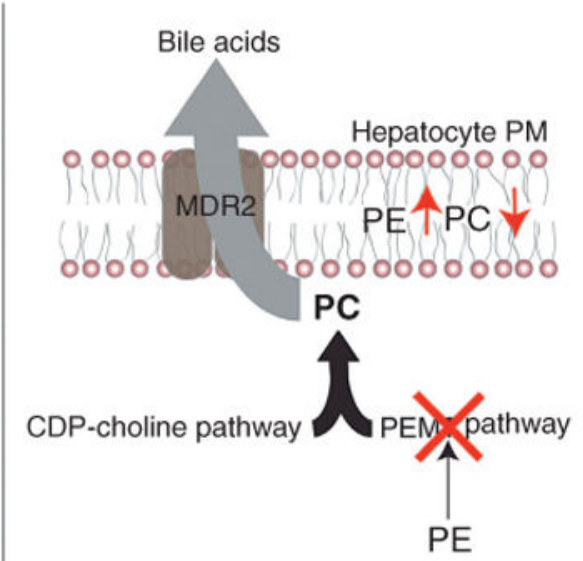

(D)

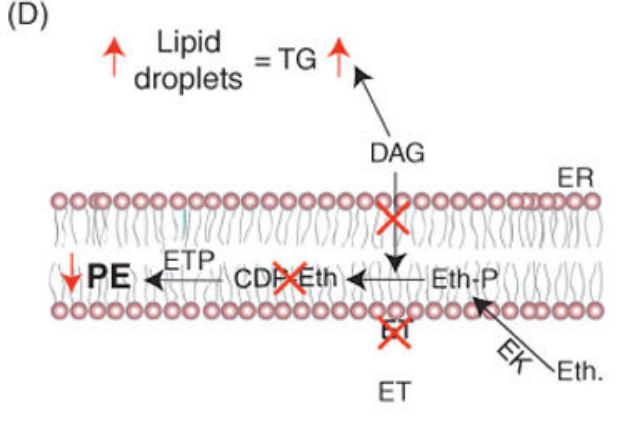

Figure 6.

PE:PC ratio in liver disease. (A) MDR2 is a PC-specific flippase that mediates the secretion of PC into bile. (B) Depletion of PC levels by ablating its synthesis via the PEMT pathway leads to an increase in the PE:PC ratio in hepatocyte membranes due to both a decrease in its synthesis as well as continued secretion by MDR2. A decrease in the levels of PC relative to PE results in leaky hepatocyte membranes causing cell lysis and subsequent tissue damage.

(C) CDP-ethanolamine pathway in hepatocytes. (D) Upon deletion of

CTP:phosphoethanolamine cytidylyltransferase in the CDP-ethanolamine pathway, the DAG that is normally used to generate CDP-ethanolamine accumulates and is instead consumed to form triglyceride (TG). Increased accumulation of triglycerides leads to the development of steatosis. EK, ethanolamine kinase. 